\title{
Comparison of mesenchymal stromal cells from peritoneal dialysis effluent with those from umbilical cords: Characteristics and therapeutic effects on chronic peritoneal dialysis in uremic rats
}

\section{Yangchun Du}

Sichuan University West China Hospital

\section{Ming Zong}

Shanghai East Hospital

\section{Qiunong Guan}

The University of British Columbia

\section{Zhongli Huang}

Sichuan University West China Hospital

\section{Lan Zhou}

Shanghai East Hospital

\section{Jing Cai}

The University of British Columbia

\section{Gerald da Roza}

The University of British Columbia

\section{Hao Wang}

Tianjin Medical University

\section{Hualin Qi}

Shanghai Pudong New Area People's Hospital

\section{Yiping Lu}

Sichuan University West China Hospital

Caigan Du ( $\sim$ caigan@mail.ubc.ca )

The University of British Columbia https://orcid.org/0000-0001-8605-5501

\section{Research}

Keywords: peritoneal dialysis, peritoneal injury, peritoneal dialysis effluent-derived mesenchymal stromal cell, cell therapy

Posted Date: April 2nd, 2021 
DOl: https://doi.org/10.21203/rs.3.rs-359679/v1

License: (c) (1) This work is licensed under a Creative Commons Attribution 4.0 International License. Read Full License

Version of Record: A version of this preprint was published at Stem Cell Research \& Therapy on July 13th, 2021. See the published version at https://doi.org/10.1186/s13287-021-02473-9. 


\section{Abstract}

Background: A long-term of peritoneal dialysis (PD) using a hypertonic PD solution (PDS) leads to patient's peritoneal membrane (PM) injury, resulting in ultrafiltration failure (UFF) and PD drop-out. Our previous study shows that PD effluent-derived mesenchymal stromal cells (pMSCs) prevent the PM injury in normal rats after repeated exposure of the peritoneal cavity to a PDS. This study was designed to compare the cytoprotection between pMSCs and umbilical cord-derived MSCs (UC-MSCs) in the treatment of both PM and kidney injury in uremic rats with chronic PD.

Methods: 5/6 nephrectomized (5/6Nx) Sprague Dawley rats were intraperitoneally (IP) injected Dianeal (4.25\% dextrose, $10 \mathrm{~mL} / \mathrm{rat} / \mathrm{d}$ ), and were treated with pMSCs or umbilical cord (UC)-MSCs (approximately $\left.2 \times 10^{6} / \mathrm{rat} / \mathrm{wk}, \mathrm{IP}\right)$. Ultrafiltration was determined by IP injection of $30 \mathrm{~mL}$ of Dianeal ( $4.25 \%$ dextrose) with 1.5-h dewell time, and kidney failure by serum creatinine ( $\mathrm{SCr}$ ) and blood urea nitrogen (BUN). The structure of the PM and kidneys was assessed using histology. Gene expression was examined using quantitative reverse transcription PCR, and protein levels using flow cytometric and Western blot analyses.

Results: We showed a slight difference in the morphology between pMSCs and UC-MSCs in plastic dishes, and significantly higher expression levels of stemness-related genes (NANOG, OCT4, SOX2, CCNA2, RAD21 and EXO1) and MSCs surface markers (CD29, CD44, CD90 and CD105) in UC-MSCs than those in pMSCs, but no difference in the differentiation to chondrocytes, osteocytes or adipocytes. pMSCs treatment was more effective than UC-MSCs in the protection of the MP and remnant kidneys in $5 / 6 \mathrm{Nx}$ rats from PDS-induced injury, which was associated with higher resistance of pMSCs than UCMSCs to uremic toxins in culture, and more reduction of peritoneal mesothelial cell death by the secretome from pMSCs than from UC-MSCs in response to PDS exposure. The secretome from both pMSCs and UC-MSCs similarly inactivated NOS2 in activated THP1 cells.

Conclusions: As compared to UC-MSCs, pMSCs may be more potently prevents PDS-induced PM and remnant kidney injury in this uremic rat model of chronic PD, suggesting that autotransplantation of ex vivo-expanded pMSCs may become a promising therapy for UFF and deterioration of remnant kidney function in PD patients.

\section{Background}

Peritoneal dialysis (PD) is an effective renal replacement therapy for end-stage renal disease (ESRD), and this therapy has increased in popularity recently [1]. During PD, a PD solution (PDS), such as glucosebased hypertonic Dianeal (1.5-4.25\% of glucose), is instilled into patient's peritoneal cavity. After 4 to $6 \mathrm{~h}$ (dwell time) of absorbing the waste substances (e.g, uremic toxins) from the blood vessels within the peritoneum, the resultant PD effluent is drained out from the cavity and discarded. As compared to hemodialysis, the benefits of using PD include technical simplicity or minimal requirement for medical staff support, more cost-effectiveness, reduced dietary restriction, better protection of residual renal 
function (RRF), improved quality of life, and lower doses of erythropoietin required [1-3]. However, the repeated PD causes chronic peritoneal inflammation [4], which is mainly caused by the bioincompatibility of PDS (acidic $\mathrm{pH}$, hyperosmolality, glucose degradation products and lactate), PD catheter-related peritoneum injury and peritonitis, and accumulating uremic toxins or the loss of RRF in PD patients [4-8]. The chronic inflammation results in structural alterations in the peritoneum including tissue fibrosis and neo-angiogenesis $[9,10]$, and consequently ultrafiltration failure (UFF) that occurs in up to $50 \%$ of PD patients after 6 years of PD [11, 12]. UFF is one of main reasons for PD drop-out [13, 14]. Therefore, successful control of PD-induced chronic peritoneal inflammation or preservation of the tissue structure of the peritoneum during the PD could prolong the PD therapy the ESRD patients need.

Mesenchymal stromal cells (MSCs), also known as mesenchymal stem cells, are characterized by the spindle or fibroblast-like plastic adherence, an unique prolife of cell surface marker expression (positive for CD29, CD44, CD73, CD90, CD105, CD106, CD166 and Stro-l; negative for CD45, CD34, CD14, CD79 and HLA-DR), and multi-lineage differentiation into mesodermal cell types under specific culture conditions $[15,16]$. MSCs have been successfully isolated from the bone marrow (BM), dental pulp, hair follicles, placenta and umbilical cord (UC), adipose tissue, synovium and testis [17-19]. We have also identified the MSCs in otherwise discarded PD effluent for the first time [20], and unlike the MSCs from other sources, these PD effluent-derived MSCs (pMSCs) are negative for CD105, Strol-1 and SSEA-4, but positive for CD200 [20, 21]. Accumulating data from both experimental models and clinical trials during the past decades have been showing the immunoregulatory effects of MSCs-based therapies on the treatment of inflammation and tissue damage [22-24]. These findings may imply the therapeutic potential of MSCs for treatment of chronic peritoneal inflammation or peritoneum damage in PD patients. Indeed, the treatment with UC-derived MSCs (UC-MSCs) significantly reduces PDS-induced tissue injury (submesothelial thickness), inflammation, angiogenesis and fibrosis of peritoneal membrane (PM), resulting in preventing UFF in a rat model of PD [25]. Recently, we also report the similar effectiveness of pMSCs on PDS-induced PM injury and PM dysfunction in rats [26]. Furthermore, a small phase I clinical

trial with 10 PD patients shows that infusion of autologous adipose tissue-derived MSCs (AD-MSCs) via cubital vein decreases the rate of solute transport (creatinine) across the PM without both the serious adverse effects and catheter-related complications in PD patients [27]. As compared with the UC-MSCs or AD-MSCs that may be restricted by the invasive harvest procedure or ethical concerns, pMSCs may offer an unlimited and promising source of MSCs as a patient-specific medical product specifically for clinical use in PD patients. The objective of this study was to compare the effectiveness between UC-MSCs and pMSCs on the protection of PM and remnant kidney of uremic rats from PDS-induced injury and dysfunction.

\section{Methods}

\section{Animals and cells}

Subtotal 5/6 nephrectomized (5/6Nx) Sprague Dawley rats (male, bodyweight: 250-350 g) were purchased from the Charles River Laboratories International, Inc. (Surgery Code: 56NEPHREX, Wilmington, 
MA, USA). Immortalized human peritoneal mesothelial cells (HPMCs) were generated in our laboratory and were grown in $\mathrm{K} 1$ complete culture medium (K1 medium) as described previously [28]. THP-1 cells, a human monocytic cell line (ATCC TIB-202), were grown in Roswell Park Memorial Institute (RPMI)-1640 medium containing $10 \%$ of fetal bovine serum (FBS) (Thermo Fisher Scientific, Ottawa, ON, Canada). Both types of cells were expanded and used for the experiments in a $5 \% \mathrm{CO}_{2}$ humidified incubator at $37^{\circ} \mathrm{C}$.

\section{Isolation and growth of pMSCs and UC-MSCs}

PD effluents were collected from anonymized patients who received Dianeal or Physioneal PD solutionbased PD therapy within 4 weeks (Suppl. Table 1). The pMSCs in the PD effluents were simply pelleted by the centrifugation and were expanded in Dulbecco's modified Eagle's medium/Ham's nutrient mixture F12 (DMEM/F12) containing 10\% FBS (Thermo Fisher Scientific) in plastic culture dishes as described previously [20]. UC-MSCs were isolated from Wharton's jelly of the UC as described previously [29]. In brief, after removing arteries and veins, the Wharton's jelly was transferred to the plastic culture dishes and were minced into small pieces or explants. The explants were incubated in the 10\% FBS-DMEM/F12 medium in a humidified $\mathrm{CO}_{2}(5 \%)$ incubator at $37^{\circ} \mathrm{C}$ until MSCs grew and migrated from the explants. The culture medium for the growth of both pMSCs and UC-MSCs was changed every 3 days, and the remaining adherent cells (70-80\% confluence) were passaged by a brief incubation with $0.25 \%$ GIBCO Trypsin/EDTA solution (Thermo Fisher Scientific). After four passages (P4), both pure pMSCs and UCMSCs (approximately $10^{6} \mathrm{cells} / \mathrm{vial}$ ) were frozen with $10 \%$ dimethylsulfoxide (DMSO) in liquid nitrogen for following in vitro and in vivo experiments.

\section{Quantitative reverse transcription-polymerase chain reaction (RT-qPCR)}

The mRNA expression of a panel of stemness markers was examined using real-time RT-qPCR and their specific primer pairs (Suppl. Table 2). Total RNA was extracted from pMSCs or UC-MSCs at P4 by using mirVana $^{\text {TM }}$ isolation kit (Ambion, Austin, TX, USA). Only the RNA samples with $\geq 8$ of RNA Integrity Number were used for RT-qPCR analysis. In brief, $1 \mu \mathrm{g}$ of high quality total RNA from each sample was reverse transcribed to cDNA by using $\mathrm{RT}^{2}$ First Strand Synthesis Kit (QIAGEN, Toronto, ON, Canada). The cDNA of a target gene was then amplified by real-time PCR using KiCqStart Probe qPCR ReadyMix ${ }^{\mathrm{TM}}$ (Product No. KCQS06) and corresponding primer pair (Suppl. Table 2) with PCR amplification conditions (3 min at $95^{\circ} \mathrm{C}$, followed by 40 cycles of $15 \mathrm{~s}$ at $95^{\circ} \mathrm{C}$ and $60 \mathrm{~s}$ at $60^{\circ} \mathrm{C}$ ) according to manufacturer's instruction (Sigma-Aldrich Canada, Oakville, ON, Canada).

The raw qPCR values of both housekeeping gene $b$-actin and the marker genes in each sample were initially collected on the threshold cycle $(\mathrm{Ct})$. A difference as a $\Delta \mathrm{Ct}$ value between the $\mathrm{Ct}$ values of a marker gene and the housekeeping $b$-actin was calculated, followed by the calculation of the double delta Ct value $(\Delta \Delta \mathrm{Ct})$, a difference between the $\Delta \mathrm{Ct}$ of the marker gene in a test sample and the average $\Delta \mathrm{Ct}$ of this gene of all the samples (as an average control). Finally, the expression fold change of the marker 
gene in a test sample relative to the average control was calculated and presented as a $2^{\mathbb{Q}-\Delta \Delta \mathrm{Ct}}$ value ( 2 to the power of negative $\Delta \Delta \mathrm{Ct}$ ) as described previously [30].

\section{Determination of cell surface expression of MSCs markers}

The cell surface expression of a panel of MSCs markers (CD14, CD29, CD34, CD44, CD45, CD73, CD79a, CD90, CD105, CD146, CD166, CD271, HLA-DR, SSEA-4 and Stro-1) on both pMSCs and UC-MSCs from the passages of 4 to 7 was measured by using fluorescence-activated cell sorting (FACS) analysis as described previously [20]. The fluorescent-conjugated monoclonal antibodies for this analysis were purchased from eBioscience (San Diego, CA, USA), Biolegend (San Diego, CA, USA) or BD Biosciences

(Mississauga, ON, Canada) (Suppl. Table 3). In brief, a single cell suspension of pMSCs or UC-MSCs from the same passage was stained with the antibodies in the dark for $30 \mathrm{~min}$ at $4^{\circ} \mathrm{C}$. After washing with PBS, the mean fluorescence intensity (MFI) of the stain of each cell surface marker was determined using a calibur flow cytometer (BD Biosciences). Data were analyzed with FlowJo software (FlowJo, LLC., Ashland, OR, USA).

\section{Trilineage differentiation}

The differentiation of pMSCs or MC-MSCs from passage 4 to 7 was induced to chondrocytes, osteocytes or adipocytes by incubation in a high glucose DMEM medium containing different mixtures of supplements as described previously $[15,20,31]$. The differentiated chondrocytes were confirmed by the presence of acidic Alcian blue-stained cartilage formation, the $\mathrm{Ca}_{2}{ }^{+}$matrix mineralization in the osteocytes was stained with Alizarin red S, and the lipid droplets inside the adipocytes were stained positively by the Oil red 0 dye.

\section{Preparation of MSCs-conditional medium (CM) for in vitro tests}

The preparation of pMSCs-CM or UC-MSC-CM was described previously [26]. In brief, the frozen MSCs after thaw were grown to be $80-90 \%$ confluent in plastic culture dishes, followed by a 24 -h incubation period with approximately $5 \mathrm{~mL}$ of the culture medium per $10^{6}$ cells. At the end of the incubation, the cellular debris in the medium was pelleted by centrifugation at $12,000 \times \mathrm{g}$ for $10 \mathrm{~min}$ at $4{ }^{\circ} \mathrm{C}$, and resultant supernatant was harvested as pMSCs-CM or UC-MSCs-CM.

\section{Chronic PD in uremic rats, and MSCs preparation and transplantation}

Chronic PM injury in 5/6Nx rats was induced by intraperitoneal (IP) injection (10 mL/day/rat) of $4.25 \%$ dextrose PDS (Dianeal, $484 \mathrm{mOsmol} / \mathrm{L}, \mathrm{pH}$ 5.2)(Baxter Healthcare, IL, USA) for a period of 6 weeks as described previously [26]. A large quantity of both pMSCs and UC-MSCs for in vivo treatment were prepared as described in our previous study [26]. In brief, frozen cells were rapidly thawed and washed once with the culture medium. The washed cells were grown in the medium in the plastic petri dishes in a $5 \% \mathrm{CO}_{2}$ humidified incubator at $37^{\circ} \mathrm{C}$ until the cell culture reached $70-80 \%$ confluent (during log phase 
of growth) as described above. Adherent MSCs were harvested by trypsinization and were suspended in phosphate buffered saline (PBS) $\left(2 \times 10^{6}\right.$ MSCs per $\mathrm{mL}$ of PBS) for rat treatment.

Four experimental groups were included in this study. Group 1 (PBS control), rats $(n=5)$ received daily PBS injection (10 mL/day/rat) only. Group 2 (PDS), rats $(n=7)$ received daily PDS and treatment with PBS vehicle (IP, $1 \mathrm{~mL} / \mathrm{rat} / \mathrm{wk}$, started at day 1$)$. Group $3(P D S+p M S C s)$, rats $(n=7)$ received daily PDS and pMSCs treatment (IP, $2 \times 10^{6}$ cells/rat/wk, started at day 1$)$. Group 4 (PDS+UC-MSCs), rats $(n=7)$ received daily PDS and UC-MSCs treatment (IP, $2 \times 10^{6}$ cells/rat/wk, started at day 1$)$. The PDS and MSCs or vehicle were administrated at different times; the PDS in the early morning ( $9 \mathrm{am}-10 \mathrm{am})$, and MSCs injection in the late afternoon (5 pm - $6 \mathrm{pm})$.

\section{Urine specimen collection}

The urine specimens were collected prior to the endpoint of MSCs treatment by using a metabolic cage. In brief, a single rat was housed in the metabolic cage and was fed ad libitum on the same food and drink water as in the "home" cages. The urine was collected during $8 \mathrm{~h}$ of the dark phase in a 12-h light/dark cycle at $25^{\circ} \mathrm{C}$, followed by centrifugation at $5,000 \times \mathrm{g}$ to pellet cellular debris. The supernatant (urine) was stored in aliquots at $-80^{\circ} \mathrm{C}$ until use.

\section{Measurement of glucose, creatinine and blood urea nitrogen}

The levels of glucose (GLU), total protein, creatinine (Cr) and blood urea nitrogen (BUN) in the fluid samples (urine, dialysate, plasma and serum) were determined using the Dimension Vista ${ }^{\circledR} 1500$ System (Siemens Healthineers Canada, Oakville, ON, Canada) in the Clinical Chemistry Laboratory at the Vancouver Coastal Health Regional Laboratory Medicine (Vancouver, BC, Canada).

\section{Function parameters of the PM and kidney}

The PM function were determined using four parameters of the peritoneal permeability or solute transport: ultrafiltration (UF), dialysate-to-plasma ratio (D/P) of GLU, and clearance of both $\mathrm{Cr}\left(\mathrm{C}_{\mathrm{Cr}}\right)$ and BUN ( $\left.\mathrm{C}_{\mathrm{BUN}}\right)$ as a primary outcome of different MSCs therapies in this study. In brief, at the end of 6-week MSCs treatment, $30 \mathrm{~mL}$ of Dianeal (4.25\% dextrose) was slowly IP injected to each rat, and it was allowed to dwell in the peritoneal cavity for $90 \mathrm{~min}$. The dialysate was recovered from the cavity using a syringe as much as possible, and the plasma isolation from the blood was done by using EDTA-containing tubes and centrifugation $\left(1500 \times \mathrm{g}, 10 \mathrm{~min}\right.$ at $\left.4^{\circ} \mathrm{C}\right)$. UF was the volume $(\mathrm{mL})$ of dialysate recovered from the cavity. Solute clearance $\left(\mathrm{C}_{\mathrm{Cr}}\right.$ and $\left.\mathrm{C}_{\mathrm{BUN}}\right)$ was calculated by multiplying the $\mathrm{D} / \mathrm{P}$ ratio of a solute with the dialysate volume ( $\left.\mathrm{D} / \mathrm{P}^{\prime} \mathrm{V}\right)$. The levels of serum $\mathrm{Cr}(\mathrm{SCr})$ and $\mathrm{BUN}$, and the protein-to- $\mathrm{Cr}$ ratio $(\mathrm{PCrR})$ in urine samples were used to measure the kidney function in $5 / 6 \mathrm{Nx}$ rats after MSCs treatment.

\section{Histopathological assessment of PM and remnant kidneys}


At the end of MSCs treatment, the structural changes in both PM and remnant kidneys were examined by histopathological assessment. In brief, two pieces of tissues on the opposite site of anterior parietal peritoneum from the injection site were collected from each rat, and the remnant kidney was split in the median longitudinally. Both peritoneal and kidney tissues were fixed in formalin (10\%) and embedded in paraffin. The tissue sections $(4 \mu \mathrm{m})$ were stained with hematoxylin and eosin (H\&E) and were scanned using Leica SCN400 Slide scanner (Leica Microsystens Inc., Concord, ON, Canada). The images of both the PM and the renal cortex were examined by using the Digital Image Hub - A slidepath Software Solution (Leica Microsystems Inc.). In the PM sections, the tissue damage was determined by the changes of both submesothelial thickness, a space from the inner surface of the muscle to the mesothelium, and the number of the blood vessels or capillaries within the submesothelial layer as previously described [26, 32]. In the kidney sections, the number of dilated tubules, including intraductal cast formation, atrophy (cell loss), and tubular cell flattening, as a mark of kidney damage was counted in each view of the renal cortical region under $100 \times$ magnification. The average number of 20 to 30 randomly selected, non-overlapping views represented the number of injured tubules in each kidney.

\section{Lactate dehydrogenase (LDH) release assay}

The sensitivity of pMSCs compared to UC-MSCs to the toxicity of a panel of uremic toxins was determined by the levels of LDH release. In brief, $0.2 \times 10^{6}$ pMSCs or UC-MSCs were seeded per well in 24well plates overnight, followed by incubation with culture medium containing different mixtures of uremic toxins (Suppl. Table 4) in a $5 \% \mathrm{CO}_{2}$ incubator at $37^{\circ} \mathrm{C}$ for $24 \mathrm{~h}$. The pMSCs or UC-MSCs incubated with $0.2 \%$ Triton X-100 were used as a positive control ( $100 \%$ of cell death). The cellular debris in the resultant supernatant was pelleted by centrifugation at 10,000 ' $\mathrm{g}$ for $5 \mathrm{~min}$, and the levels of LDH in the supernatants were determined by using the Cytotoxicity Detection Kit (LDH) (Roche) (Sigma-Aldrich Canada) following manufacturer's protocol. The cell death of pMSCs or UC-MSCs in response to the uremic toxin mixture was calculated as follows: $\mathrm{LDH}$ release $(\%)=$ sample $\mathrm{OD}_{450} /$ positive control $\mathrm{OD}_{450}$. $100 \%$.

\section{Measurement of cytoprotection of pMSCs-CM or UC-MSCs-CM in vitro}

The cytoprotective activity of pMSCs-CM as compared to that of UC-MSCs-CM was determined in cultured HPMCs after a brief direct exposure to a hypertonic PDS, PDS-induced cell death. A monolayer of HPMCs after overnight incubation with K1 medium was treated with the culture medium only (Medium group) or with Dianeal (4.25\% dextrose) for 20 min. After 20 min-treatment, these PDS-treated cells were further treated with the culture medium only (100\% culture medium, PDS group) or the medium containing either $50 \%(\mathrm{v} / \mathrm{v})$ pMSCs-CM (PDS+pMSCs) or 50\% (v/v) UC-MSCs-CM (PDS+UC-MSCs) in a $5 \% \mathrm{CO}_{2}$ incubator at $37^{\circ} \mathrm{C}$ for $24 \mathrm{~h}$. The cell apoptosis or viability was quantitatively determined by using FACS analysis with double staining of Annexin-V conjugated with phycoerythrin (Annexin-V-PE) and 7amino-actinomycin D (7-AAD) as described in our previous study [33].

\section{Inactivation of monocytes/macrophages by pMSCs-CM or UC-MSCs-CM in vitro}


Human THP-1 monocyte cultures (approximately $10^{5} \mathrm{cell} / \mathrm{s} / \mathrm{mL}$ ) were activated or induced to macrophage differentiation by addition of phorbol 12-myristate 13-acetate (PMA) first, followed by additional stimulation with lipopolysaccharides (LPS) as described previously [26]. The activated THP-1 cells were subsequently treated with the culture medium alone (100\% culture medium, PMA/LPS group) or the medium containing either 50\% (v/v) pMSCs-CM (PMA/LPS+pMSCs) or 50\% (v/v) UC-MSCs-CM (PMA/LPS+UC-MSCs) in a $5 \% \mathrm{CO}_{2}$ incubator at $37^{\circ} \mathrm{C}$ for $24 \mathrm{~h}$. The unstimulated THP1 cells after $24 \mathrm{~h}$ incubation with the culture medium were used as a baseline control (Medium group).

\section{Nitric oxide (NO) measurement}

After $24 \mathrm{~h}$ of treatment with pMSCs-CM, UC-MSCs-CM or medium control, the levels of nitrite as a product of NO by oxidation in the supernatant were measured using the Griess method [26]. In brief, $50 \mu \mathrm{L}$ of culture supernatant were first incubated with $50 \mu \mathrm{L}$ of $1 \%$ sulfanilamide in $5 \%$ phosphoric acid (96-well plates in triplicates) for $10 \mathrm{~min}$, followed by addition of $50 \mu \mathrm{L} /$ well of $0.1 \%$ naphthylethyline diamine dihydrochloride. The color development was quantitatively measured at $550 \mathrm{~nm}$, and the level of $\mathrm{NO} /$ nitrite in each sample was calculated using a standard curve with known sodium nitrite concentrations.

\section{Western blot analysis}

After $24 \mathrm{~h}$ of treatment with pMSCs-CM, UC-MSCs-CM or medium control, total cellular protein extracts from THP-1 cells were harvested, and the protein levels of nitric oxide synthase 2 (NOS 2) were determined by Western blot as described previously [26, 34]. In brief, the cellular protein extracts (approximately $100 \mu \mathrm{g}$ protein/sample) were fractionated by $7 \%$ SDS-polyacrylamide gel electrophoresis (SDS-PAGE), and were transferred onto a nitrocellulose membrane. NOS 2 protein bands were specifically detected by primary rabbit polyclonal anti-NOS 2 antibody (N-20) (Santa Cruz Biotech, Santa Cruz, CA, USA) and secondary goat anti-rabbit IgG antibody (Vector Lab., Burlingame, CA, USA). The blots were reprobed using anti-b-actin (Sigma-Aldrich Canada) for confirmation of the amount of loaded protein in each sample.

\section{Statistical analysis}

Data were presented as the mean \pm standard deviation (SD). The differences between groups were compared by using analysis of variance (ANOVA) or $t$-tests (two-tailed distribution) of Prism GraphPad software (GraphPad Software, Inc., La Jolla, CA, USA) as appropriate. A $p$ value of $\leq 0.05$ was considered significant.

\section{Results}

\section{Differences of MSC characteristics between pMSCs and UC-MSCs}


The differences in the microscopic morphology, expression of stemness genes and MSC surface markers, and multipotential differentiation between pMSCs and UC-MSCs were compared under the same conditions. As shown in Fig. 1a, both pMSCs and UC-MSCs equally adhered to and expanded on the surface of plastic tissue culture plates in cultures. The morphology of pMSCs was characterized by a spindle shape, whereas UC-MSCs displayed more the characteristic cobble-stone or "fibroblast" morphology. The stemness of pMSCs and UC-MSCs was determined by the relative mRNA expression of a panel of "stemness markers" - NANOG, C-MYC, KLF4, OCT4, SOX2, LIN28, CCNA2, MCM6, RAD21, STAGE1 and EXO1 to $\beta$-Actin using RT-qPCR. The Ct (cycle threshold) values of all the target genes except NANOG and LIN28 were under 30 cycles (strong positive). The Ct of NANOG was 32 to 36 cycles in pMSCs and 33 to 38 cycles in UC-MSCs (moderate levels), and the expression of LIN28was not detectable (Ct $>40$ cycles) in 3 of 9 pMSCs samples (the remaining: 31-33 cycles) and 2 of 7 UC-MSCs samples (the remaining: $34-39$ cycles) (weak levels). The relative expression of a target gene was presented by the $2^{-D D C t}$ to $\beta$-Actin in each sample (Fig. 1b). The statistical analysis suggested that the expression of NANOG $(p=0.0169)$, OCT4 $(\mathrm{p}=0.0284)$, SOX2 $(p=0.034), \operatorname{CCNA2}(p=0.0223), R A D 21(p=$ $0.0272)$ and $\operatorname{EXO1}(p=0.039)$ was significantly higher in UC-MSCs $(\mathrm{n}=7)$ than those in pMSCs $(\mathrm{n}=9)$, and the levels of $C-M Y C(p=0.0595)$ and MCM6 $(p=0.0648)$ were quite higher in UC-MSCs than pMSCs. The remaining genes (KLF4, LIN28 and STAG1) were not different.

The expression profile of a panel of MSC cell surface markers between pMSCs $(n=6)$ and UC-MSCs $(n=$ 9) was also compared. Fig. 2a presented a typical histogram of each marker in FACS analysis in both groups. As shown in Fig. 2b, a high level or strong positive (MFl: $\geq 2000)$ was seen in the expression of CD29, CD44, CD73 or CD90 in both groups and of CD166 in 3 of 9 UC-MSCs samples, and a low to moderate level (MFI: 400 - 2000) in CD105, CD146 and CD166 in UC-MSCs and CD146 and CD166 in pMSCs. The expression of the remaining markers were very low to negative including CD105 in pMSCs. The statistical comparison of the levels of these positive markers indicated that except CD73 ( $p=$ $0.4353), \operatorname{CD} 146(p=0.1899)$ and $\operatorname{CD} 166(p=0.3762)$, the expression of CD29 $(p=0.0167), \operatorname{CD} 44(p=$ $0.0422), \operatorname{CD} 90(p=0.0096)$ and $\operatorname{CD} 105(p=0.0058)$ was significantly higher in the UC-MSCs than those in the pMSCs (Fig. 2b).

The in vitro multipotential differentiation between pMSCs and UC-MSCs was compared and confirmed. As shown in Fig. 3, both pMSCs and UC-MSCs could be induced to osteocytes, adipocytes and chondrocytes under the same in vitro conditions without any marked difference.

\section{Different potencies between pMSCs and UC-MSCs in the prevention of hypertonic PDS-induced PM dysfunction and tissue injury}

The PM injury of 5/6Nx rat was induced by daily exposed to Dianeal PDS, and some of them received the treatment of either pMSCs or UC-MSCs $\left(2 \times 10^{6}\right.$ cells). As shown in Fig. 4, as compared with PBS control $(n=5)$, the daily IP injection of PDS alone (PDS group, $n=7)$ significantly damaged the function of PM, evidenced by the significantly lower values of UF ( $p=0.0169)$, GLU D/P ratios $(p=0.0016), \mathrm{C}_{\mathrm{Cr}}(p=$ $0.0412)$ and $\mathrm{C}_{\mathrm{BUN}}(p=0.0171)$. As compared to PDS group, an increase in PM functional parameters was 
seen in PDS+pMSCs group ( $\mathrm{n}=7$ )(UF: $p=0.0174$; GLU D/P: $p=0.0173 ; \mathrm{C}_{\mathrm{Cr}}: p=0.0082$; and $\mathrm{C}_{\mathrm{BUN}}: p=$ 0.0127), but not in PDS+UC-MSCs group $(n=7)$ that was indicated by no significant differences of the PM parameters between PDS and PDS-UC-MSCs groups. These data suggested that pMSCs were more potent than UC-MSCs in the prevention of the PDS-induced PM dysfunction

The levels of PM tissue damage, including the thickness of submesothelial layer and the number of blood vessels and capillaries, were examined using histologic analysis. Fig. 5a presented a typical microscopic view of the PM tissues in each group, showing the affected submesothelial layer and the blood vessels and capillaries. A semi-quantitative histologic analysis revealed that the submesothelial layer in PDS group (194.71 $\pm 112.33 \mu \mathrm{m}, \mathrm{n}=7$ ) was significantly thicker than that $(72.18 \pm 13.45 \mu \mathrm{m}, \mathrm{n}=5)$ in PBS group ( $p=0.0377$ ), suggesting that daily exposure to the PDS induced the thickness of the PM (Fig. $5 \mathrm{~b}$ ). After pMSCs treatment, the thickness of the submesothelial layer $(73.22 \pm 13.2 \mu \mathrm{m}, \mathrm{n}=7)$ was similar to that in the PBS group and was significantly reduced as compared to that in the PDS group $(p=0.0148)$. In contrast to the pMSCs, administration of UC-MSCs did reduce the layer thickness to $104.46 \pm 28.14 \mu \mathrm{m}$ $(n=7)$ but not significantly $(p=0.0616)$ (Fig. $5 b)$ in this limited number of rats. Similarly to the submesothelial layer, the numbers of the blood vessels and capillaries in PDS group were significantly higher than those in PBS group $(p=0.0041)$, and were decreased by the treatment with pMSCs (PDS vs. PDS+pMSCs, $p=0.0052$ ) but not with UC-MSCs (PDS vs. PDS+UC-MSCs, $p=0.0585$ ) (Fig. $5 c$ ). All these data suggested pMSCs were more effective than UC-MSCs on the protection of the PM from PDS-induced structural modification.

\section{Different potencies between pMSCs and UC-MSCs in the prevention of hypertonic PDS-worsened kidney failure}

Subtotal $5 / 6 \mathrm{Nx}$ in rats is a common experimental model of chronic kidney disease [35]. Thus, the secondary outcome measure of MSCs treatments (pMSCs vs UC-MSCs) was their effects on the progression of kidney failure in these rats. As shown in Fig. 6, daily intraperitoneal exposure to the PDS worsened the kidney failure, indicated by the elevated levels of $\operatorname{BUN}(p=0.0401), \operatorname{SCr}(p=0.0560)$ and PCR in urine ( $p=0.0078)$ as compared to those in PBS group. The treatment with pMSCs but not with UCMSCs significantly prevented the increase in both BUN $(p=0.0120)$ and $\operatorname{SCr}(p=0.0067)$ as compared to those in the PDS group (Figs. 6a and 6b). Interestedly, both types of MSCs suppressed the urinary PCr induced by the exposure to the PDS although the decreased levels were slightly different - from $1.35 \pm$ 0.84 in PDS group to $0.24 \pm 0.11$ by pMSCs $(p=0.0047)$ or to $0.44 \pm 0.17$ by UC-MSCs $(p=0.0165)$ (Fig. $6 c)$.

The additional evidence of MSCs treatment for the protection of damaged kidneys was further confirmed by the histologic analysis. As shown in Fig. 7a, tubule dilation was the most noticeable pathological change in the tissue sections. A semi-quantitative histologic assessment of these dilated tubules revealed that the number of the dilated tubules per view in PDS group $(10.73 \pm 3.48, n=7)$ was significantly more than that $(1.86 \pm 1.15, \mathrm{n}=5)$ in PBS group $(p=0.0003)$. Furthermore, the treatment with pMSCs significantly prevented the tubule dilation in the kidneys as the less dilation $(3.26 \pm 1.92)$ in this group 
than that in the PDS $(p=0.0003, \mathrm{n}=7)$, which was not seen in the kidneys of the rats receiving UC-MSCs $(p=0.5459)$ (Fig. 7b).

\section{Difference in susceptibility to uremic toxins between pMSCs and UC-MSCs}

When the kidneys fail, a variety of uremic toxins are accumulated in the patient's body [36], suggesting that MSCs that have potential for using as a therapy for ESRD patients need to survive under the uremic toxin environment. LDH release as a biomarker of cell death was measured in cultured pMSCs and UCMSCs following incubation with different concentrations of a panel of uremic toxin (Suppl. Table 4). As shown in Fig. 8, there was more cell death in UC-MSCs than pMSCs after incubation with the same amounts of uremic toxins $(p<0.0001$, two-way ANOVA). For example, the incubation with 100-20 mixture of uremic toxins induced $32.5 \pm 6.97 \%$ of LDH release from UC-MSCs as compared to $21.25 \pm 1.28 \%$ from pMSCs $(p=0.0005, \mathrm{n}=8)$. These data suggested that pMSCs were more resistant than UC-MSCs to the toxicity of these uremic toxins found in the body of PD patients.

\section{Different cytoprotection and NOS 2 inhibition of secretome from pMSCs and UC-MSCs in vitro}

There are various pathways responsible for therapeutic potential of MSCs including their secretome [37, 38]. In this study, the effects of the secretome, derived from both pMSCs and UC-MSCs, on the survival of HPMCs following exposure to a PDS and NOS 2 activity, an inflammatory mediator, of activated monocytes (THP-1 cells) were compared. A typical graph from each group showed the survived/viable (Q4: double negative population) and apoptotic cells (total of Q2 and Q3: Annexin-V staining positive) in FACS analysis (Fig. 9a). A 20-min exposure to the $4.35 \%$ dextrose Dianeal PDS significantly reduced the viability of cultured HPMCs from $87.07 \pm 3.4 \%$ in Medium to $75.63 \pm 6.39 \%$ in PDS-treated group $(p=$ $0.0031, \mathrm{n}=6)$ (Fig. 9b) or induced the apoptosis from $11.19 \pm 2.68 \%$ to $21.93 \pm 5.89 \%(p=0.0023, \mathrm{n}=6)$ (Fig. 9c). The PDS-induced cell death was significantly prevented by the supernatant from pMSCs, in which the cell viability in the PDS was increased to $84.65 \pm 3.83 \%$ in PDS+pMSCs $(p=0.0140, \mathrm{n}=6)$ (Fig. $9 \mathrm{~b})$, or the cell apoptosis from the PDS group was decreased to $13.23 \pm 2.87 \%(p=0.0086, \mathrm{n}=6)$ (Fig. 9c). However, the cytoprotection of the supernatant from UC-MSCs was not as significant as that from pMSCs in the prevention of PDS-induced cell death of cultured HPMCs.

The therapeutic actions of the secretome derived from pMSCs and UC-MSCs were further compared in the inhibition of NOS 2 expression and activity in the activated monocytes. As shown in Fig. 10, following activation of THP-1 by incubation with PMA and LPS, THP-1 cells up-regulated NOS 2 protein level and produced an abundant amount of $\mathrm{NO}$ in the medium, from $15.88 \pm 4.61 \mu \mathrm{M}$ in the medium alone to 47.88 $\pm 14.28 \mu \mathrm{M}$ in the medium containing PMA/LPD $(p<0.0001, \mathrm{n}=8)$. The up-regulation of NOS 2 protein and NO production by the stimulation with PMA/LPS were significantly inhibited by the supernatants from both pMSCs (NO levels: $25.75 \pm 9.65 \mu \mathrm{M}$, PMA/LPS vs PMA/LPS+pMSCs, $p=0.0027, \mathrm{n}=8$ ) and UC-MSCs (NO levels: $17.5 \pm 9.87 \mu \mathrm{M}$, PMA/LPS vs PMA/LPS+UC-MSCs, $p=0.0002, \mathrm{n}=8$ ) cultures (Fig. 10). These data implied that the secretome derived from pMSCs and UC-MSCs might have similar capacity in the suppression of NOS 2 activity in the inflammatory monocytes/macrophages. 


\section{Discussion}

There has been a very broad interest in clinical application of MSCs and their products (e.g. extracellular vesicles or secretome) for tissue damage repair, fibrosis prevention, immunomodulation and antiinflammation in various pathologies, including the peritoneal inflammation and fibrosis (see recent reviews: [25, 39-41]). At present, the MSCs in clinical studies are mainly isolated from the BM, adipose or perinatal (e.g. UC and placenta) tissues [42]. However, the selection of using autologous MSCs from a patient's own body has several advantages over allogeneic MSCs such as availability, no need of HLA matching and/or immunosuppression and no risk of graft-versus-host disease, but there are practical limitations to extraction of these cells such as the difficulty and invasiveness of the procurement [43]. We for the first time isolated the MSCs from otherwise "discarded" PD fluids - pMSCs [20]. The clinical use of these autologous pMSCs specifically for controlling peritoneal inflammation or preserving PM structure during PD in PD patients has all the benefits as mentioned above, plus the unlimited availability without any additional "invasive" harvest. We previously demonstrated the effectiveness of pMSCs on the protection of PM from Dianeal PDS (4.25\% glucose)-induced morphological alteration, neo-angiogenesis and functional loss (fluid removal) in healthy rats [26]. To further confirm the feasibility of using pMSCs for prevention of PDS-induced peritoneal inflammation in PD patients, in this study we compared the effectiveness of the pMSCs with that of UC-MSCs on the PDS-induced peritoneal inflammation in uremic rats. The in vivo results revealed that pMSCs were more effective than UC-MSCs in the protection of both the PM and remnant kidney from PDS (4.25\% dextrose Dianeal)-initiated damage in the preclinical rat model. These data were supported by the more survived pMSCs than UC-MSCs in the presence of uremic toxins and the higher activity of the secreted bioactive factors (secretome) from pMSCs than those from UC-MSCs in the prevention of PDS-induced peritoneal mesothelial cell death. Interestedly, the expression levels of stemness and MSC key markers of perinatal UC-MSCs were higher than those in adult tissuesourced pMSCs, which were correlated with a higher growth rate of UC-MSCs than that of pMSCs (data not shown) but not with their cytoprotective activities in both in vitro and in vivo.

In general, the survival and potency are two essential requirements for the in vivo effectiveness of administered human MSCs in rats. The survival or fate of grafted human MSCs in host rodents may depend on the site or microenvironment of cell injection, where the immune response to "foreign" antigens are different. It has been reported that some human UC-MSCs after injection to the brain or BM cavity of rats could survive for 1 to 2 months [44-46]. However, the presence of human BM-MSCs is not detectable after 1 week of injection into the myocardium where there is a significant macrophage infiltration in the rats [47]. After human BM-MSCs injected into the peritoneal cavity of immunocompetent mice, these human cells initially aggregate with macrophages but are disappeared within a week [48]. Similarly, IP injected rat BM-MSCs into isogeneic rat recipients can not be found in the peritoneal mesothelium after 3 days of transplantation [49]. In both present and previous studies [26], we could not localize any of injected human cells (both pMSCs and UC-MSCs) in the PM sections by immunohistochemical staining of human nuclear antigen at the experimental endpoint (at day 7 after the last injection) (data not shown). All these studies may suggest that the MSCs regardless of their source only survive for a short period of time (no longer than a week) in the peritoneal cavity of rats. We did not 
compare the immunophenotypic profile of pMSCs with UC-MSCs in present study, but UC-MSCs are more sensitive than pMSCs in cultures to the cytotoxicity of uremic toxins that are slowly accumulated in the body with kidney failure (Fig. 8). This observation may imply that the survival of pMSCs may be longer such as a few more hours than that of UC-MSCs in uremic rats after IP injection, which however remains further investigation.

Therapeutic actions of MSCs during a MSCs-based therapy are complex and may be differently affected at the different site or environment of the body [50-52], which mainly include tissue protection by cytoprotection and differentiation into multiple cell lineages and regulation of immune responses via immunomodulation. The potential for cell trilineage differentiation in vitro is similar between pMSCs and UC-MSCs (Fig. 2), and no evidence is seen that these human cells differentiate into peritoneal mesothelial cells in rats. Although the mechanism of MSCs action has not been completely understood, numerous studies have demonstrated the extracellular secreted factors and vesicles-their secretome as their "active ingredients" for regenerative and cytoprotective effects, and immunomodulatory property of the MSCsbased therapy [53,54]. MSCs-derived soluble factors and vehicle-bound substances (secretome or conditional medium) from different sources consist of IFN-g, IL-17, IL-10, IL-6, TGF-b, IL-2, TNF-a and HLA (for immunomodulation), and GDNF, FGF, IGF, BDNF, PEGF, PDGF, miRNAs, VEGF and MMPs (for cell survival/growth and tissue remodeling) [55-57]. The composition of the secretome of MSCs appears to vary significantly, depending on the age of the host and niches where the cells are collected [56,57], which may be true in our present study - pMSCs from the peritoneum of aging donors versus UC-MSCs from new-born babies. Indeed, we tested and compared the cytoprotection and macrophage inactivation of the secretome (conditional medium) from pMSCs with that from UC-MSC. Fig. 9 indicated that the secretome of pMSCS is more protective than that of UC-MSCs against a PDS-induced peritoneal mesothelial cell death. Other studies have shown that HGF of MSCs-derived secretome inhibits TGF- $\beta 1$ induced epithelial-mesenchymal transition of HPMCs [49] and/or stimulates mesothelial cell proliferation [58]. Whether the levels of HGF in the secretome from pMSCs are higher than that from UC-MSCs are unknown.

There are a large numbers of infiltrating macrophages in the parietal peritoneum biopsies from the predialysis stage, which is specifically associated with higher PD technique failure and mortality in PD patients $[59,60]$, suggesting that macrophages play an important role in the initiation of peritoneal inflammation in PD patients. After IP injection, human MSCs immediately aggregate with macrophages [48], and the macrophages are the target of MSCs for their immunoregulatory property via both active and passive mechanisms - both complicated [52]. The active mechanisms are via secretion of soluble factors such as TSG-6, PGE2 and lactate and others (e.g. TGF- $\beta 3$, thrombospondin 1, IL-6) that drives M1 proinflammatory phenotype of macrophages toward an $\mathrm{M} 2$ anti-inflammatory phenotype for inflammation suppression or tissue repair $[52,61-63]$. The passive mechanisms of MSCs in regulation of macrophages include the intracellular signaling regulators, such as miRNA in secretome and mitochondria which are shuttled to the cell membrane of MSCs during mitophage [52]. The miRNAs downregulate Toll-like receptor signaling and upregulate cytokine production (e.g. IL-10), while phagocytosis of mitochondria from MSCs improved the bioenergetics of macrophages [52]. Using a PCR 
array analysis, we has demonstrated that pMSC-derived CM or secretome downregulate the proinflammatory gene expression (i.e., CXCL6, NOS 2, IL1RN, CCL5, and NR3C1), while upregulate antiinflammatory genes (i.e., CCR1, CCR4, IL-9, and IL-10) in activated macrophages [26]. Further, the inhibition of NOS 2 expression or activity by both pMSCs- and UC-MSCs derived-CM was similar (Fig. 10). However, whether there is any difference between pMSCs and UC-MSCs in both active and passive regulatory pathways of macrophages remains further investigation.

The limitation of this study was largely related to the experimental model. First, the pathogenesis of PM injury in uremic rat model may not be the same as in PD patients although both are uremic and exposed to a hypertonic PDS. Second, the possible occurrence of xeno-immunity stimulated by human MSCs in rats that could affect their therapeutic actions such as survival. Third, human MSCs may exhibit different biological functions in different hosts - rats versus humans, particularly in the situation of using pMSCs as cell autotransplantation and UC-MSCs as cell allotransplantation. In addition, the molecule mechanisms underlying the cytoprotection and immunoregulatory functions of both pMSCs and UCMSCs are not investigated. For example, which secreted molecule(s) from MSCs protect mesothelial cells from apoptosis, and which inactivate macrophages or switch macrophage phenotype from M1 (an inflammatory mediator) to M2 (a tissue healing mediator), and the mechanisms by which the pMSCs-CM are more protective than UC-MSCs-CM in the situation of PDS-induced mesothelial cell death..

\section{Conclusions}

Recently, there has been an increasing interest in using MSCs to protect the PM of PD patients from injury during PD. IP injection of rat BM-MSCs or human AD-MSCs and pMSCs significantly reduces PDSinduced submesothelial thickness and cellular infiltration of the PM $[26,58,64]$. The present study demonstrates the different effectiveness between pMSCs and UC-MSCs in the prevention of PDS-induced peritoneal alterations including peritoneal thickening and neo-angiogenesis that associate with protection of UF (both fluid removal, and BUN and Cr clearance), and in the preservation of remnant kidney function. Taken together, all these findings may provide preclinical evidence for a novel approach by using MSCs, particularly pMSCs from PD patient's own body, in the treatment of PM alternations and residual kidney failure in PD patients.

\section{Declarations}

\section{Acknowledgements}

We thank staff at Peritoneal Dialysis Unit at Royal Columbian Hospital (New Westminster, BC, Canada) for collecting peritoneal dialysis effluents, and BC Children's Hospital BioBank (Vancouver, BC) for umbilical cord collection.

\section{Author's contributions}


$\mathrm{GdR}, \mathrm{HW}, \mathrm{HQ}, \mathrm{YL}$ and $\mathrm{CD}$ conceived the idea or conception. YD, MZ, and CD designed the experiments. YD, $\mathrm{MZ}, \mathrm{QG}, \mathrm{ZH}, \mathrm{CZ}$ and $\mathrm{JC}$ performed the experiments and data analyses. CD performed the histological examination. $Y D, M Z, Q G$ and $C D$ performed data interpretation. $C D$ was a major contributor in writing the manuscript. All authors proofread and approved the final manuscript.

\section{Funding}

This work was supported by the Canadian Institutes of Health Research (to CD and GdR), the Project of Health Department of Sichuan Province (to YD, project No.: 30305030236), the Science and Technology Commission of Shanghai Municipality (to HQ, No.: 20ZR1449800), the National Natural Science Foundation of China (to ZM, No.: 81601407), Talent Development Program of Pudong New Area Health and Family Planning Commission (to ZM, No.: PWRq2017-03) and Talent Development Program of " new star of medicine" (to ZM, HWRS(2020) No. 087).

\section{Availability of data and materials}

All the data used to support the findings of this study are included within the article, and are also available from the corresponding author (Caigan Du) upon request.

\section{Ethics approval and consent to participate}

The use of the animals for this study (protocol: A19-0089) was approved by the Animal Experiments Ethical Committee of the University of British Columbia following the guideline of the Canadian Council on Animal Care. PD effluents were collected from patients under the protocol H15-02466, and UCs from donors (both genders) with informed consent of the mother under the protocol H18-01234, which were approved by the Clinical Research Ethics Board at the University of British Columbia (Vancouver, BC, Canada) in accordance with the Canadian Tri-council policy statement: Ethical conduct for research involving humans.

\section{Consent for publication}

Not applicable

\section{Competing interests}

The authors declare no conflict of interest.

\section{Author details}

${ }^{1}$ Department of Urology, Institute of Urology, West China Hospital of Sichuan University, Chengdu, No. 17, Section 3, Ren Min Nan Road, Chengdu, Sichuan, 610041, China

${ }^{2}$ Organ Transplantation Center, Sichuan Provincial People's Hospital, University of Electronic Science and Technology of China, 32\# W. Section 2, 1st Ring Rd, Chengdu, Sichuan, 610072, China 
${ }^{3}$ Department of Urologic Sciences, The University of British Columbia, 2660 Oak Street, Vancouver, BC, V6Y 1K2, Canada

${ }^{4}$ Shanghai East Hospital, Tongji University School of Medicine, 150 Jimo Road, Pudong New District, Shanghai, 200120, China

${ }^{5}$ Division of Nephrology, Department of Medicine, The University of British Columbia, 1081 Burrard Street, Vancouver, BC, V6Z 1Y6, Canada

${ }^{6}$ Department of General Surgery, Tianjin Medical University General Hospital, 154 Anshan Road, Heping, Tianjin, 300052, China

${ }^{7}$ Department of Nephrology, Shanghai Pudong New Area People's Hospital, No. 490 Chuanhuan South Road, Pudong New Area, Shanghai, 201299, China

\section{Abbreviations}

7-AAD: 7-Amino-actinomycin D

$A D$ : adipose tissue

ANOVA: Analysis of variance

BM: Bone marrow

BUN: Blood urea nitrogen

CM: Conditional medium

Cr: Creatinine

Ct: Threshold cycle

DMEM/F1: Dulbecco's modified Eagle's medium/Ham's nutrient mixture F12

DMSO: Dimethylsulfoxide

D/P: Dialysate-to-plasma ratio

ESRD: End-stage renal disease

FACS: Fluorescence-activated cell sorting

FBS: Fetal bovine serum

GLU: Glucose 
H\&E: Hematoxylin and eosin

HPMCs: Human peritoneal mesothelial cells

IP: Intraperitoneal injection

LDH: Lactate dehydrogenase

LPS: Lipopolysaccharides

MFI: Mean fluorescence intensity

MSCs: Mesenchymal stromal cells

NO: Nitric oxide

NOS 2: Nitric oxide synthase 2

Nx: Nephrectomized

P4: Four passages

PAGE: Polyacrylamide gel electrophoresis

PBS: Phosphate buffered saline

PCr: Protein-to-creatinine ratio

PD: Peritoneal dialysis

PDS: Peritoneal dialysis solution

PE: Phycoerythrin

PM: Peritoneal membrane

PMA: Phorbol 12-myristate 13-acetate

pMSCs: Peritoneal dialysis effluent-derived mesenchymal stromal cells

RPMI: Roswell Park Memorial Institute

RRF: Residual renal function

RT-qPCR: Quantitative reverse transcription-polymerase chain reaction

SCr: Serum creatinine 
SD: Standard deviation

UC: Umbilical cord

UFF: Ultrafiltration failure

\section{References}

1. Jain AK, Blake P, Cordy P, Garg AX. Global trends in rates of peritoneal dialysis. J Am Soc Nephrol. 2012;23(3):533-44.

2. Karopadi AN, Mason G, Rettore E, Ronco C. Cost of peritoneal dialysis and haemodialysis across the world. Nephrol Dial Transplant. 2013;28(10):2553-69.

3. Chuasuwan A, Pooripussarakul S, Thakkinstian A, Ingsathit A, Pattanaprateep O. Comparisons of quality of life between patients underwent peritoneal dialysis and hemodialysis: a systematic review and meta-analysis. Health Qual Life Outcomes. 2020;18(1):191.

4. Baroni G, Schuinski A, de Moraes TP, Meyer F, Pecoits-Filho R. Inflammation and the peritoneal membrane: causes and impact on structure and function during peritoneal dialysis. Mediators Inflamm. 2012;2012:912595.

5. Strippoli GF, Tong A, Johnson D, Schena FP, Craig JC. Catheter type, placement and insertion techniques for preventing peritonitis in peritoneal dialysis patients. Cochrane Database Syst Rev. 2004(4):CD004680.

6. Flessner MF. Inflammation from sterile dialysis solutions and the longevity of the peritoneal barrier. Clin Nephrol. 2007;68(6):341-8.

7. Higuchi $\mathrm{C}$, Nishimura $\mathrm{H}$, Sanaka T. Biocompatibility of peritoneal dialysis fluid and influence of compositions on peritoneal fibrosis. Ther Apher Dial. 2006;10(4):372-9.

8. Cho Y, Hawley CM, Johnson DW. Clinical causes of inflammation in peritoneal dialysis patients. Int J Nephrol. 2014;2014:909373.

9. Kalk P, Ruckert M, Godes M, von Websky K, Relle K, Neumayer HH, et al. Does endothelin B receptor deficiency ameliorate the induction of peritoneal fibrosis in experimental peritoneal dialysis? Nephrol Dial Transplant. 2010;25(5):1474-8.

10. Krediet RT. Ultrafiltration failure is a reflection of peritoneal alterations in patients treated with peritoneal dialysis. Front Physiol. 2018;9:1815.

11. Kawaguchi $Y$, Hasegawa $T$, Nakayama M, Kubo H, Shigematu T. Issues affecting the longevity of the continuous peritoneal dialysis therapy. Kidney Int Suppl. 1997;62:105-7.

12. Heimburger $O$, Waniewski J, Werynski A, Tranaeus A, Lindholm B. Peritoneal transport in CAPD patients with permanent loss of ultrafiltration capacity. Kidney Int. 1990;38(3):495-506.

13. Chaudhary K. Peritoneal dialysis drop-out: causes and prevention strategies. Int J Nephrol. 2011;2011:434608. 
14. Kawaguchi Y, Ishizaki T, Imada A, Oohira S, Kuriyama S, Nakamoto H, et al. Searching for the reasons for drop-out from peritoneal dialysis: a nationwide survey in Japan. Perit Dial Int. 2003;23(Suppl 2):175-7.

15. Dominici M, Le Blanc K, Mueller I, Slaper-Cortenbach I, Marini F, Krause D, et al. Minimal criteria for defining multipotent mesenchymal stromal cells. The International Society for Cellular Therapy position statement. Cytotherapy. 2006;8(4):315-7.

16. Pittenger MF, Mackay AM, Beck SC, Jaiswal RK, Douglas R, Mosca JD, et al. Multilineage potential of adult human mesenchymal stem cells. Science. 1999;284(5411):143-7.

17. da Silva Meirelles L, Chagastelles PC, Nardi NB. Mesenchymal stem cells reside in virtually all postnatal organs and tissues. J Cell Sci. 2006;119(Pt 11):2204-13.

18. Gonzalez R, Griparic L, Vargas V, Burgee K, Santacruz P, Anderson R, et al. A putative mesenchymal stem cells population isolated from adult human testes. Biochem Biophys Res Commun. 2009;385(4):570-5.

19. Sedgley CM, Botero TM. Dental stem cells and their sources. Dent Clin North Am. 2012;56(3):54961.

20. Liu B, Guan Q, Li J, da Roza G, Wang H, Du C. Mesenchymal stroma cells in peritoneal dialysis effluents from patients. Hum Cell. 2017;30(2):51-9.

21. Han B, Zhou L, Guan Q, da Roza G, Wang H, Du C. In Vitro Expansion and characterization of mesenchymal stromal cells from peritoneal dialysis effluent in a human protein medium. Stem Cells Int. 2018;2018:5868745.

22. Wang $M$, Yuan Q, Xie L. Mesenchymal stem cell-based immunomodulation: properties and clinical application. Stem Cells Int. 2018;2018:3057624.

23. Gao F, Chiu SM, Motan DA, Zhang Z, Chen L, Ji HL, et al. Mesenchymal stem cells and immunomodulation: current status and future prospects. Cell Death Dis. 2016;7:e2062.

24. Wu X, Jiang J, Gu Z, Zhang J, Chen Y, Liu X. Mesenchymal stromal cell therapies: immunomodulatory properties and clinical progress. Stem Cell Res Ther. 2020;11(1):345.

25. Alatab S, Najafi I, Atlasi R, Pourmand G, Tabatabaei-Malazy O, Ahmadbeigi N. A systematic review of preclinical studies on therapeutic potential of stem cells or stem cells products in peritoneal fibrosis. Minerva Urol Nefrol. 2018;70(2):162-78.

26. Zhou L, Zong M, Guan Q, da Roza G, Wang H, Qi H, et al. Protection of the peritoneal membrane by peritoneal dialysis effluent-derived mesenchymal stromal cells in a rat model of chronic peritoneal dialysis. Stem Cells Int. 2019;2019:8793640.

27. Alatab S, Shekarchian S, Najafi I, Moghadasali R, Ahmadbeigi N, Pourmand MR, et al. Systemic infusion of autologous adipose tissue-derived mesenchymal stem cells in peritoneal dialysis patients: feasibility and safety. Cell J. 2019;20(4):483-95.

28. Mendelson AA, Guan Q, Chafeeva I, da Roza GA, Kizhakkedathu JN, Du C. Hyperbranched polyglycerol is an efficacious and biocompatible novel osmotic agent in a rodent model of peritoneal dialysis. Perit Dial Int. 2013;33(1):15-27. 
29. Van Pham P, Truong NC, Le PT, Tran TD, Vu NB, Bui KH, et al. Isolation and proliferation of umbilical cord tissue derived mesenchymal stem cells for clinical applications. Cell Tissue Bank. 2016;17(2):289-302.

30. Livak KJ, Schmittgen TD. Analysis of relative gene expression data using real-time quantitative PCR and the $2^{-\Delta \Delta C t}$ Method. Methods. 2001;25(4):402-8.

31. Fitzsimmons REB, Mazurek MS, Soos A, Simmons CA. Mesenchymal stromal/stem cells in regenerative medicine and tissue engineering. Stem Cells Int. 2018;2018:8031718.

32. Du C, Mendelson AA, Guan Q, Dairi G, Chafeeva I, da Roza G, et al. Hyperbranched polyglycerol is superior to glucose for long-term preservation of peritoneal membrane in a rat model of chronic peritoneal dialysis. J Transl Med. 2016;14(1):338.

33. Chu TL, Guan Q, Nguan CY, Du C. Halofuginone synergistically enhances anti-proliferation of rapamycin in $\mathrm{T}$ cells and reduces cytotoxicity of cyclosporine in cultured renal tubular epithelial cells. PLoS One. 2015;10(12):e0144735.

34. Jia Y, Guan Q, Guo Y, Du C. Reduction of inflammatory hyperplasia in the intestine in colon cancerprone mice by water-extract of Cistanche deserticola. Phytother Res. 2012;26(6):812-9.

35. Renczes E, Maronek M, Gaal Kovalcikova A, Vavrincova-Yaghi D, Tothova L, Hodosy J. Behavioral changes during development of chronic kidney disease in rats. Front Med (Lausanne). 2019;6:311.

36. Vanholder R, De Smet R, Glorieux G, Argiles A, Baurmeister U, Brunet P, et al. Review on uremic toxins: classification, concentration, and interindividual variability. Kidney Int. 2003;63(5):1934-43.

37. Harrell CR, Fellabaum C, Jovicic N, Djonov V, Arsenijevic N, Volarevic V. Molecular mechanisms responsible for therapeutic potential of mesenchymal stem cell-derived secretome. Cells. 2019;8(5):467.

38. Eleuteri S, Fierabracci A. Insights into the secretome of mesenchymal stem cells and its potential applications. Int J Mol Sci. 2019;20(18):4597.

39. Regmi S, Pathak S, Kim JO, Yong CS, Jeong JH. Mesenchymal stem cell therapy for the treatment of inflammatory diseases: challenges, opportunities, and future perspectives. Eur J Cell Biol. 2019;98(5-8):151041.

40. Yin S, Ji C, Wu P, Jin C, Qian H. Human umbilical cord mesenchymal stem cells and exosomes: bioactive ways of tissue injury repair. Am J Transl Res. 2019;11(3):1230-40.

41. Pittenger MF, Discher DE, Peault BM, Phinney DG, Hare JM, Caplan Al. Mesenchymal stem cell perspective: cell biology to clinical progress. NPJ Regen Med. 2019;4:22.

42. Viswanathan S, Shi Y, Galipeau J, Krampera M, Leblanc K, Martin I, et al. Mesenchymal stem versus stromal cells: International Society for Cell \& Gene Therapy (ISCT(R)) Mesenchymal Stromal Cell committee position statement on nomenclature. Cytotherapy. 2019;21(10):1019-24.

43. Han Y, Li X, Zhang Y, Han Y, Chang F, Ding J. Mesenchymal stem cells for regenerative medicine. Cells. 2019;8(8):886. 
44. Huang PY, Shih YH, Tseng YJ, Ko TL, Fu YS, Lin YY. Xenograft of human umbilical mesenchymal stem cells from Wharton's jelly as a potential therapy for rat pilocarpine-induced epilepsy. Brain Behav Immun. 2016;54:45-58.

45. Lin YC, Ko TL, Shih YH, Lin MY, Fu TW, Hsiao HS, et al. Human umbilical mesenchymal stem cells promote recovery after ischemic stroke. Stroke. 2011;42(7):2045-53.

46. Fu YS, Lu CH, Chu KA, Yeh CC, Chiang TL, Ko TL, et al. Xenograft of human umbilical mesenchymal stem cells from Wharton's jelly differentiating into osteocytes and reducing osteoclast activity reverses osteoporosis in ovariectomized rats. Cell Transplant. 2018;27(1):194-208.

47. Grinnemo KH, Mansson A, Dellgren G, Klingberg D, Wardell E, Drvota V, et al. Xenoreactivity and engraftment of human mesenchymal stem cells transplanted into infarcted rat myocardium. J Thorac Cardiovasc Surg. 2004;127(5):1293-300.

48. Bazhanov N, Ylostalo JH, Bartosh TJ, Tiblow A, Mohammadipoor A, Foskett A, et al. Intraperitoneally infused human mesenchymal stem cells form aggregates with mouse immune cells and attach to peritoneal organs. Stem Cell Res Ther. 2016;7:27.

49. Ueno T, Nakashima A, Doi S, Kawamoto T, Honda K, Yokoyama Y, et al. Mesenchymal stem cells ameliorate experimental peritoneal fibrosis by suppressing inflammation and inhibiting TGF-beta1 signaling. Kidney Int. 2013;84(2):297-307.

50. Moll G, Hoogduijn MJ, Ankrum JA. Editorial. Safety, Efficacy and mechanisms of action of mesenchymal stem cell therapies. Front Immunol. 2020;11:243.

51. Fan XL, Zhang Y, Li X, Fu QL. Mechanisms underlying the protective effects of mesenchymal stem cell-based therapy. Cell Mol Life Sci. 2020;77(14):2771-94.

52. Carty F, Mahon BP, English K. The influence of macrophages on mesenchymal stromal cell therapy: passive or aggressive agents? Clin Exp Immunol. 2017;188(1):1-11.

53. Fernandes TL, Kimura HA, Pinheiro CCG, Shimomura K, Nakamura N, Ferreira JR, et al. Human synovial mesenchymal stem cells good manufacturing practices for articular cartilage regeneration. Tissue Eng Part C Methods. 2018;24(12):709-16.

54. Vizoso FJ, Eiro N, Cid S, Schneider J, Perez-Fernandez R. Mesenchymal stem cell secretome: toward cell-free therapeutic strategies in regenerative medicine. Int J Mol Sci. 2017;18(9):1852.

55. Pinho AG, Cibrao JR, Silva NA, Monteiro S, Salgado AJ. Cell secretome: basic insights and therapeutic opportunities for CNS disorders. Pharmaceuticals (Basel). 2020;13(2):31.

56. Kumar LP, Kandoi S, Misra R, Vijayalakshmi S, Rajagopal K, Verma RS. The mesenchymal stem cell secretome: a new paradigm towards cell-free therapeutic mode in regenerative medicine. Cytokine Growth F R. 2019;46:1-9.

57. Ahangar P, Mills SJ, Cowin AJ. Mesenchymal stem cell secretome as an emerging cell-free alternative for improving wound repair. Int J Mol Sci. 2020;21(19):7038.

58. Kim H, Mizuno M, Furuhashi K, Katsuno T, Ozaki T, Yasuda K, et al. Rat adipose tissue-derived stem cells attenuate peritoneal injuries in rat zymosan-induced peritonitis accompanied by complement activation. Cytotherapy. 2014;16(3):357-68.

Page 22/32 
59. Contreras-Velazquez JC, Soto V, Jaramillo-Rodriguez Y, Samaniego-Rios LI, Quinones-Perez V, Avila $\mathrm{M}$, et al. Clinical outcomes and peritoneal histology in patients starting peritoneal dialysis are related to diabetic status and serum albumin levels. Kidney Int Suppl. 2008(108):S34-41.

60. Sawai A, Ito Y, Mizuno M, Suzuki Y, Toda S, Ito I, et al. Peritoneal macrophage infiltration is correlated with baseline peritoneal solute transport rate in peritoneal dialysis patients. Nephrol Dial Transplant. 2011;26(7):2322-32.

61. Prockop DJ. Concise review: two negative feedback loops place mesenchymal stem/stromal cells at the center of early regulators of inflammation. Stem Cells. 2013;31(10):2042-6.

62. Lee DK, Song SU. Immunomodulatory mechanisms of mesenchymal stem cells and their therapeutic applications. Cell Immunol. 2018;326:68-76.

63. English K. Mechanisms of mesenchymal stromal cell immunomodulation. Immunol Cell Biol. 2013;91(1):19-26.

64. Tulpar S, Poyrazoglu MH, Ozbilge H, Bastug F, Gunduz Z, Torun YA, et al. Modulation of inflammation by mesenchymal stem cell transplantation in peritoneal dialysis in rats. Ren Fail. 2012;34(10):131723.

\section{Figures}

Figure 1

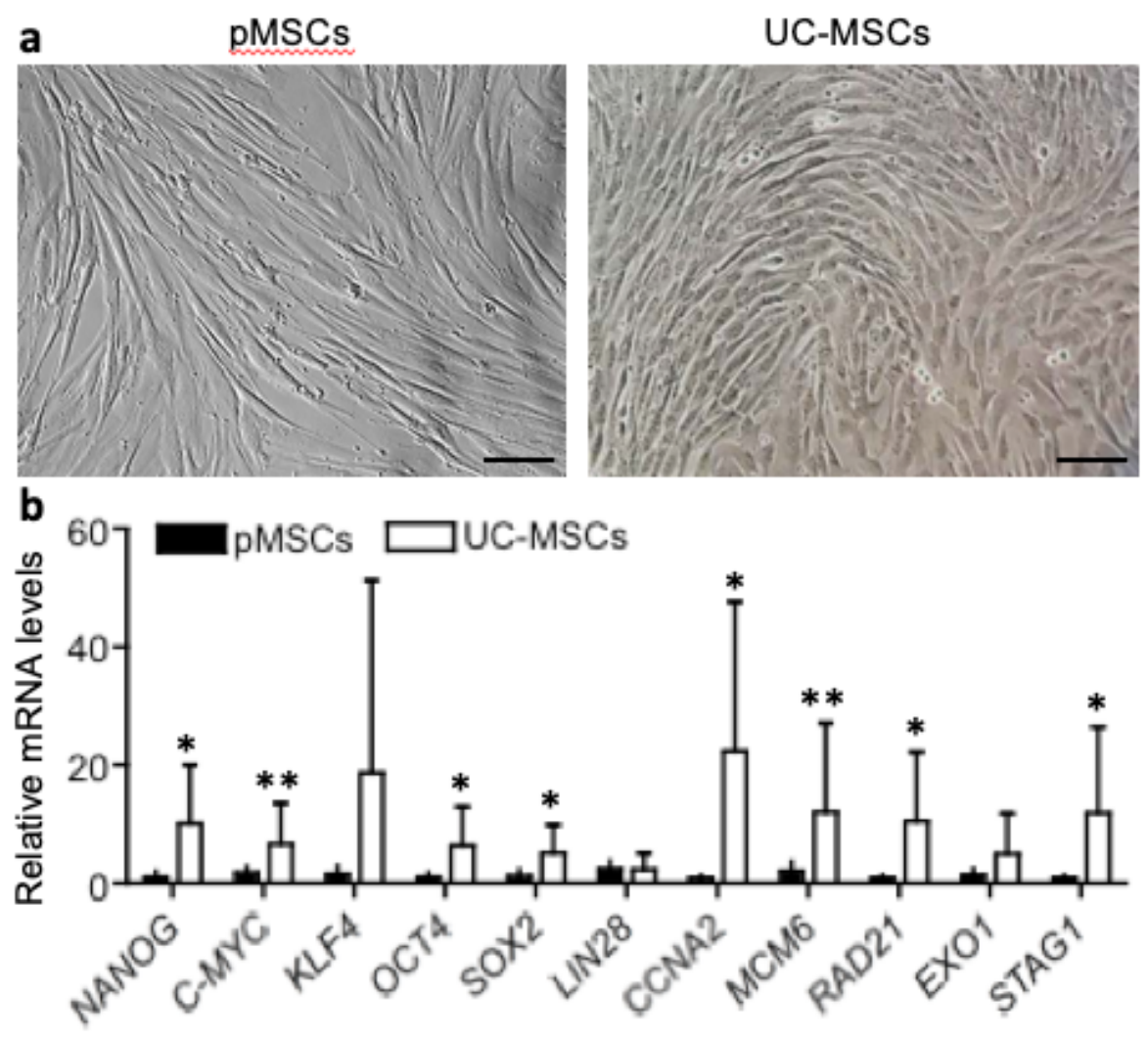




\section{Figure 1}

Morphology and stemness marker gene expression between pMSCs and UC-MSCs at P4. (a) A typical microscopic image of a confluent monolayer of pMSCs or UC-MSCs growing in plastic tissue culture plates. pMSCs displayed a spindle shape, and UC-MSCs cobble-stone like morphology. Bar: $100 \mu \mathrm{m}$ (b) The expression (relative mRNA) of a panel of stemness marker genes, which was presented as fold changes (2囚- $\triangle \Delta \mathrm{Ct}$ ) and determined using RT-qPCR as compared to the internal $\beta$-Actin control. Data are presented as the mean \pm standard deviation (SD). The different expression of a gene in between pMSCs $(\mathrm{n}=9)$ and UC-MSCs $(\mathrm{n}=7)$ was analyzed using two-tailed t-test. *Statistically significant (NANOG, $\mathrm{p}=$ 0.0169; OCT4, $p=0.0284$; SOX2, $p=0.034$; CCNA2, $p=0.0223$; RAD21, $p=0.0272$; and EX01, $p=0.039$ ), **marginally significant (C-MYC, $p=0.0595 ; M C M 6, p=0.0648)$. This experiment was repeated three times in triplicate using independently prepared cDNAs, and the results were exhibited in almost identical patterns.

\section{Figure 2}
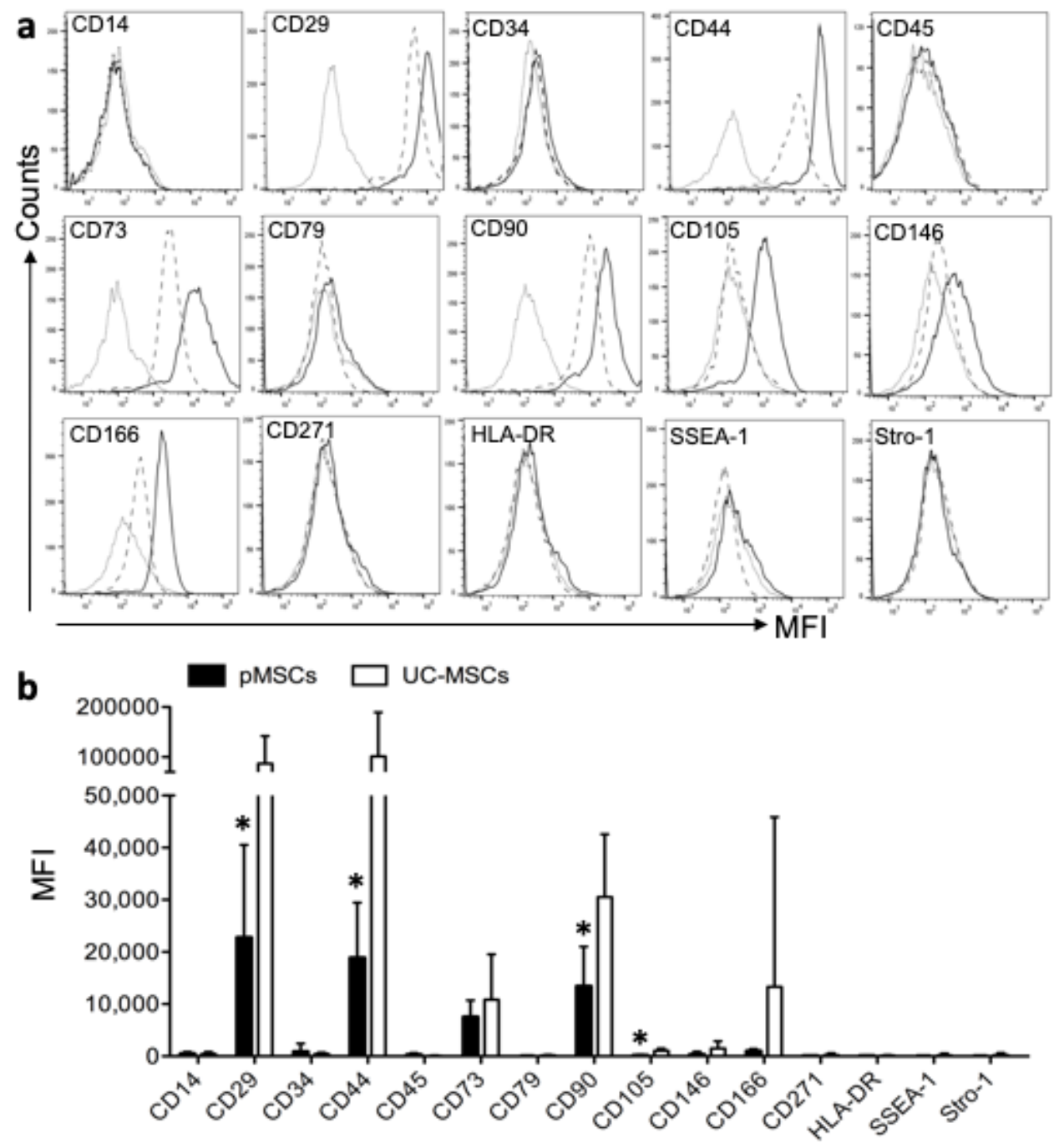

Figure 2

Expression of a panel of MSC typical cell surface markers between pMSCs and UC-MSCs at P4. (a) A typical FACS histogram of each marker expression. A faint line: background staining; a dot line: pMSCs; 
and a slid line: UC-MSCs. MFI: mean fluorescence intensity. (b) Data are presented as the mean \pm SD. The different expression of a cell surface marker in between pMSCs $(n=9)$ and UC-MSCs $(n=7)$ was analyzed using two-tailed t-test. *Statistically significant (CD29, $p=0.0167 ; C D 44, p=0.0422 ; C D 90, p=$ 0.0096; CD105, $p=0.0058$ ),

\section{Figure 3}

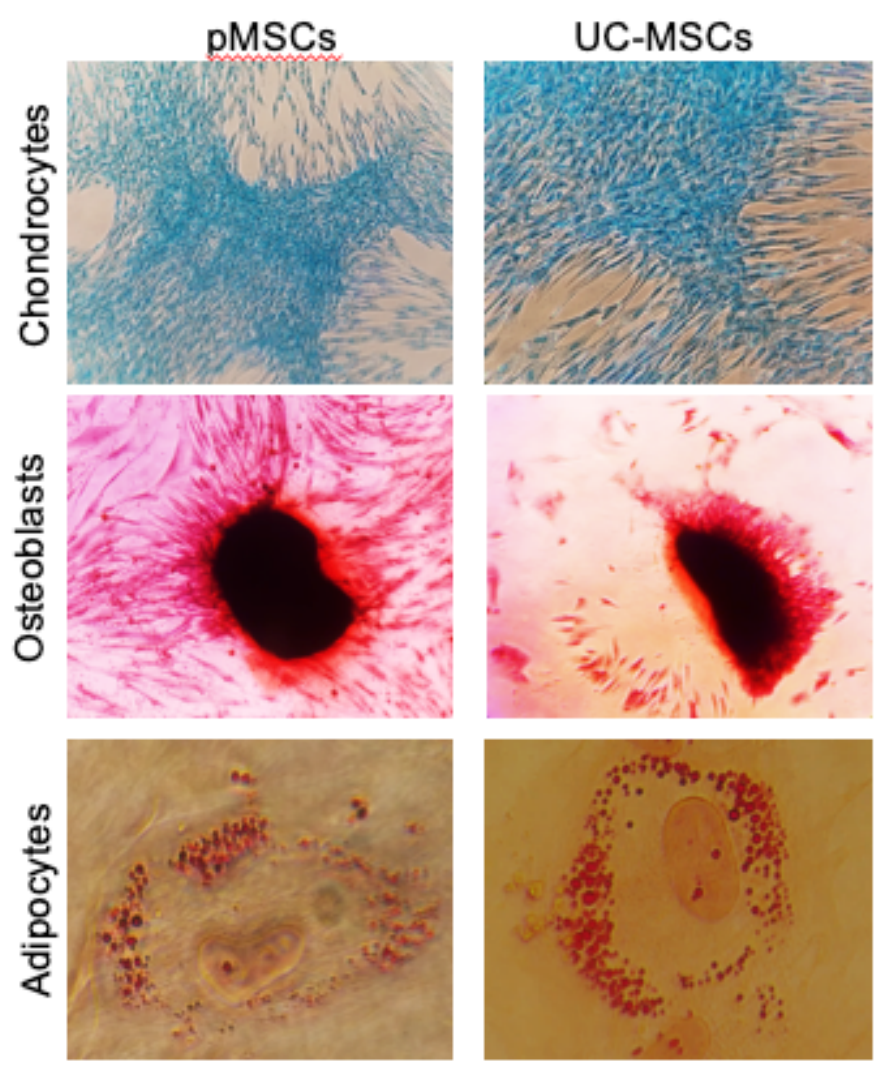

\section{Figure 3}

Trilineage differentiation to the chondrocytes, osteocytes, and adipocytes. Data are a typical microscopic view of differentiated cells from one representative experiment, which were repeated three times separately. 


\section{Figure 4}
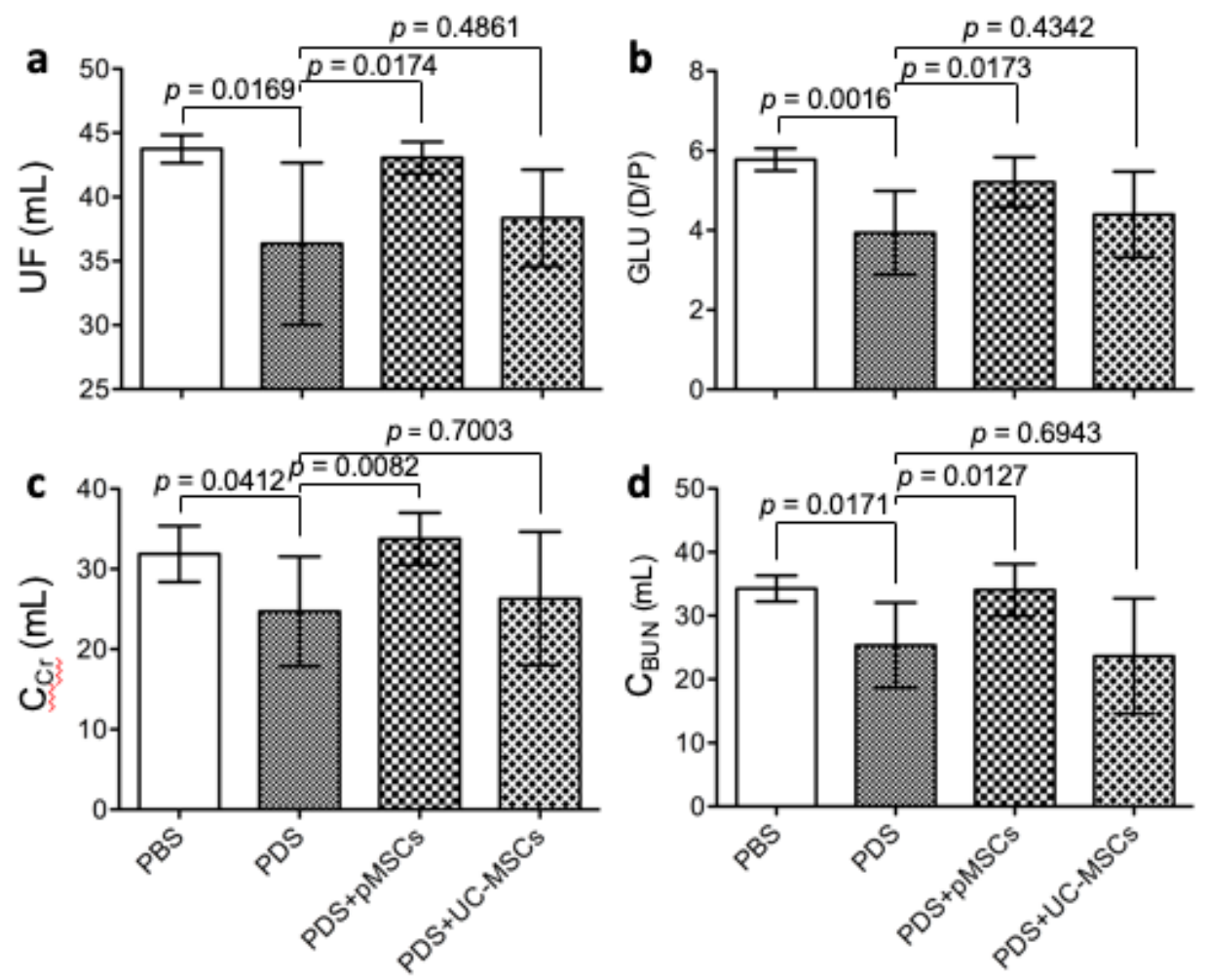

Figure 4

PM function after treatment with either pMSCs or UC-MSCs. The PM function at the experimental endpoint was determined by the measurement of ultrafiltration (UF) (a), the glucose dialysate-to-plasma ratio (GLU D/P) (b), creatinine clearance (CCr) (c), and BUN clearance (CBUN) (d). Data are presented as the mean \pm SD of each group (PBS: $n=5$; PDS: $n=7$; PDS+pMSCs: $n=7$; and PDS+UC-MSCs: $n=7$ ). The difference between groups was analyzed using two-tailed t-test. 
Figure 5
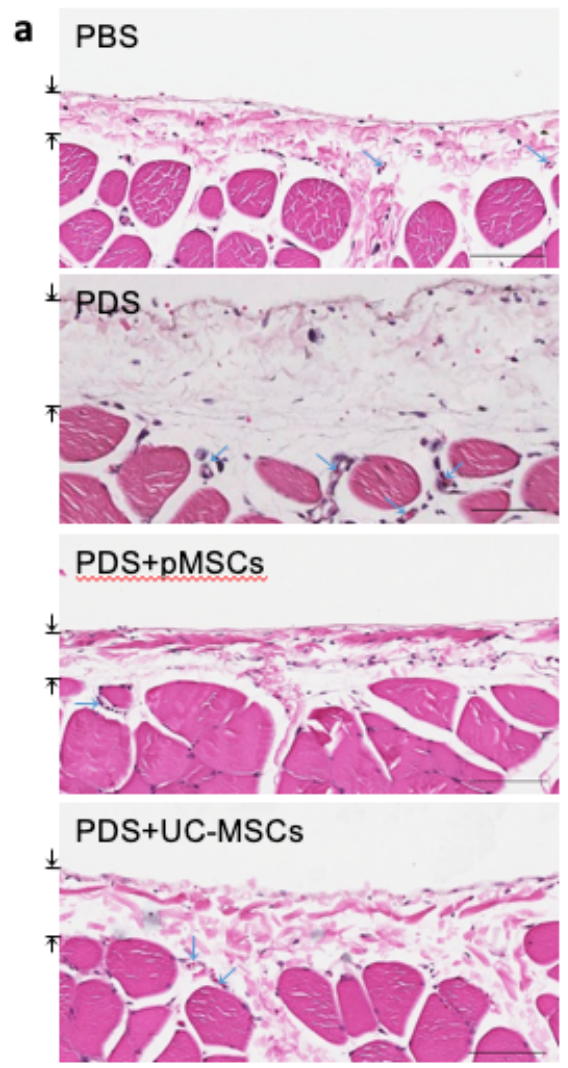

b
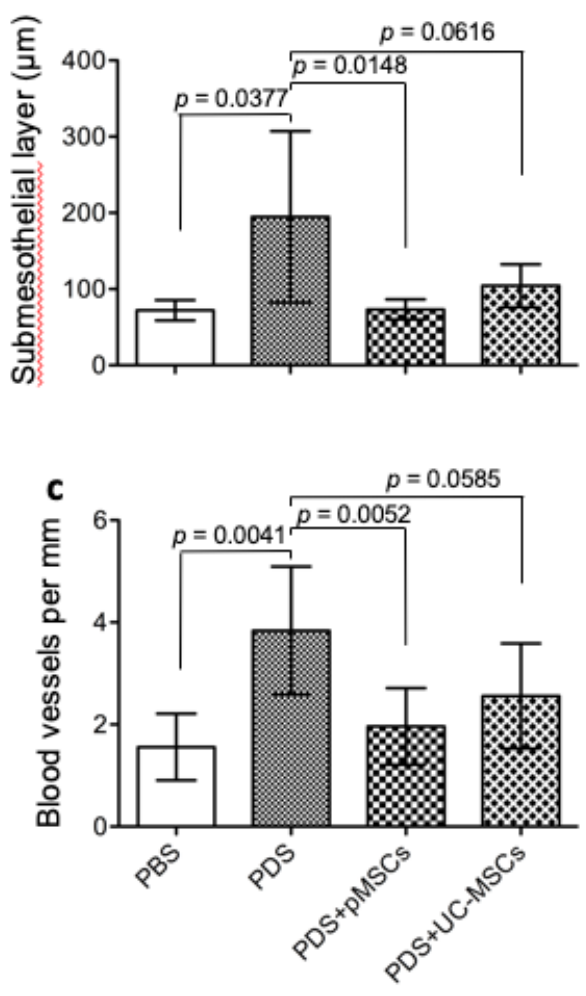

\section{Figure 5}

Histologic analysis of the structural damage of the PM. (a) Typical microscopic views of H\&E-stained PM for each group. The thickness of submesothelial layer was indicated by the area between two arrows. Blue arrows: blood vessels and capillaries, bar: $100 \mu \mathrm{m}$. (b) The thickness of the submesothelial layer in each group (PBS: $n=5$; PDS: $n=7$; PDS+pMSCs: $n=7$; and PDS+UC-MSCs: $n=7$ ). Data are presented as the mean \pm SD. The difference between groups was analyzed using two-tailed t-test. (c) The number of the blood vessels and capillaries within the submesothelial layer (as a measure of neoangiogenesis) in each group (PBS: $n=5$; PDS: $n=7$; PDS+pMSCs: $n=7$; and PDS+UC-MSCs: $n=7$ ). Data are presented as the mean $\pm S D$. The difference between groups was analyzed using two-tailed t-test. 
Figure 6

a
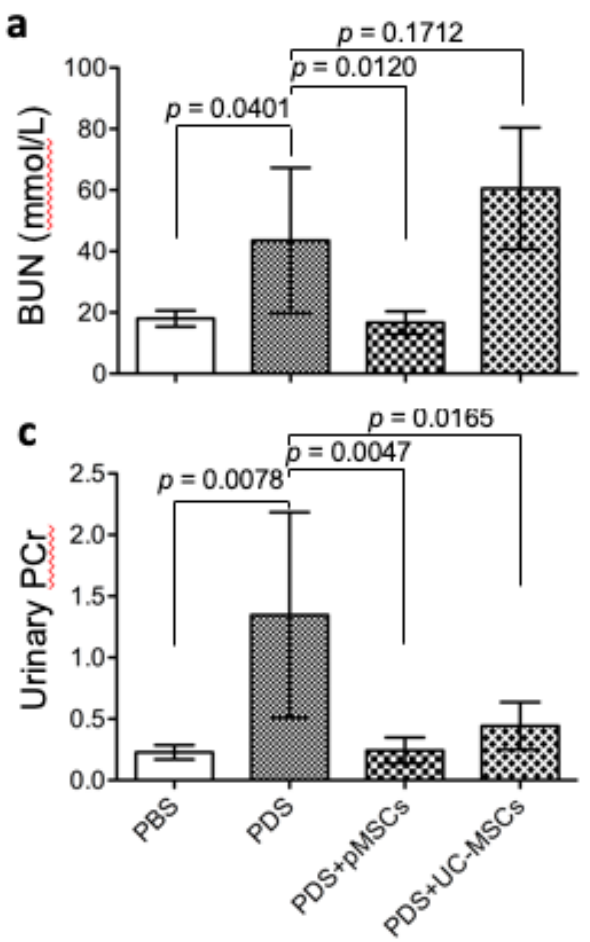

b

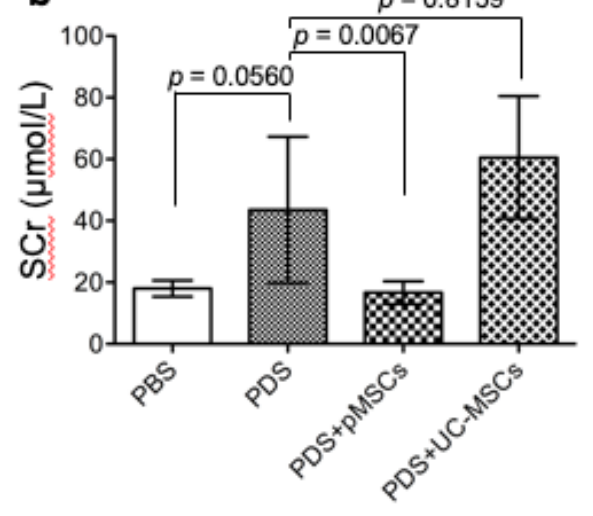

\section{Figure 6}

Remnant kidney function after treatment with either pMSCs or UC-MSCs. The remnant kidney function at the experimental endpoint was determined by the measurement of serum BUN (a), serum creatinine ( $\mathrm{SCr}$ ) (b) and the protein-to-creatinine ratio in urine (urinary $\mathrm{PCr}$ ). Data are presented as the mean $\pm \mathrm{SD}$ of each group (PBS: $n=5$; PDS: $n=7$; PDS+pMSCs: $n=7$; and PDS+UC-MSCs: $n=7$ ). The difference between groups was analyzed using two-tailed t-test. 
Figure 7
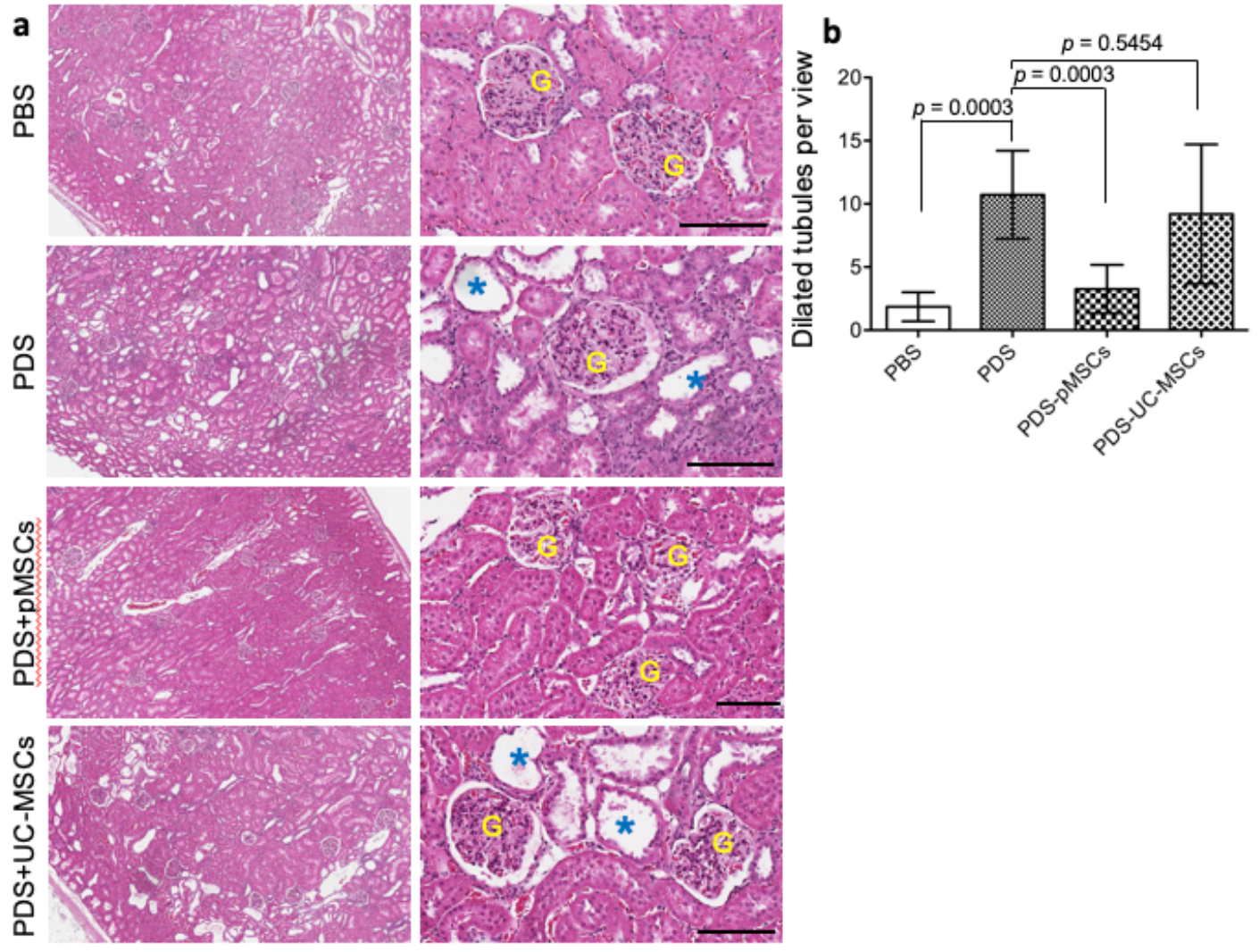

\section{Figure 7}

Histologic assessments of kidney tissue damage. (a) Typical microscopic views of the renal cortex (H\&E stain) for each group. The left hand column: low power images; the right hand column: high power images. G: glomerulus, *: dilated tubules, Bar: $100 \mu \mathrm{m}$. (b) Tissue sections were viewed under 100 $\times$ magnification, and the numbers of dilated tubules in the renal cortex were counted. Data are presented as the mean \pm SD. The difference between groups was compared using two-tailed t-test. 
Figure 8

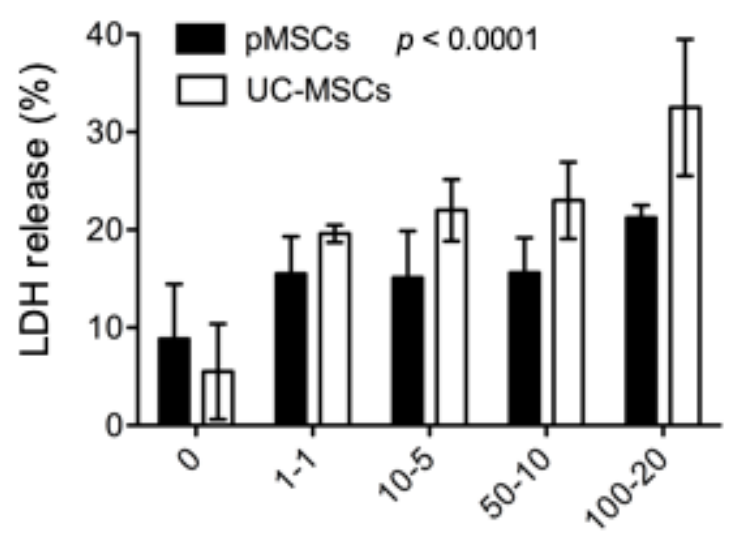

Uremic toxin mixture

Figure 8

Different sensitivity of between pMSCs and UC-MSCs to the cytotoxicity of a panel of uremic toxins. A monolayer of pMSCs or MC-MSCs was incubated with different concentrations of a panel of common uremic toxins (Suppl Table 4) for $24 \mathrm{~h}$. The cell death of MSCs was determined by LDH release. Data are presented as the mean \pm SD of each group $(0, n=4 ; 1-1: n=6$; remaining groups: $n=8)$. The difference between pMSCs and UC-MSCs was compared using two-way ANOVA. 


\section{Figure 9}
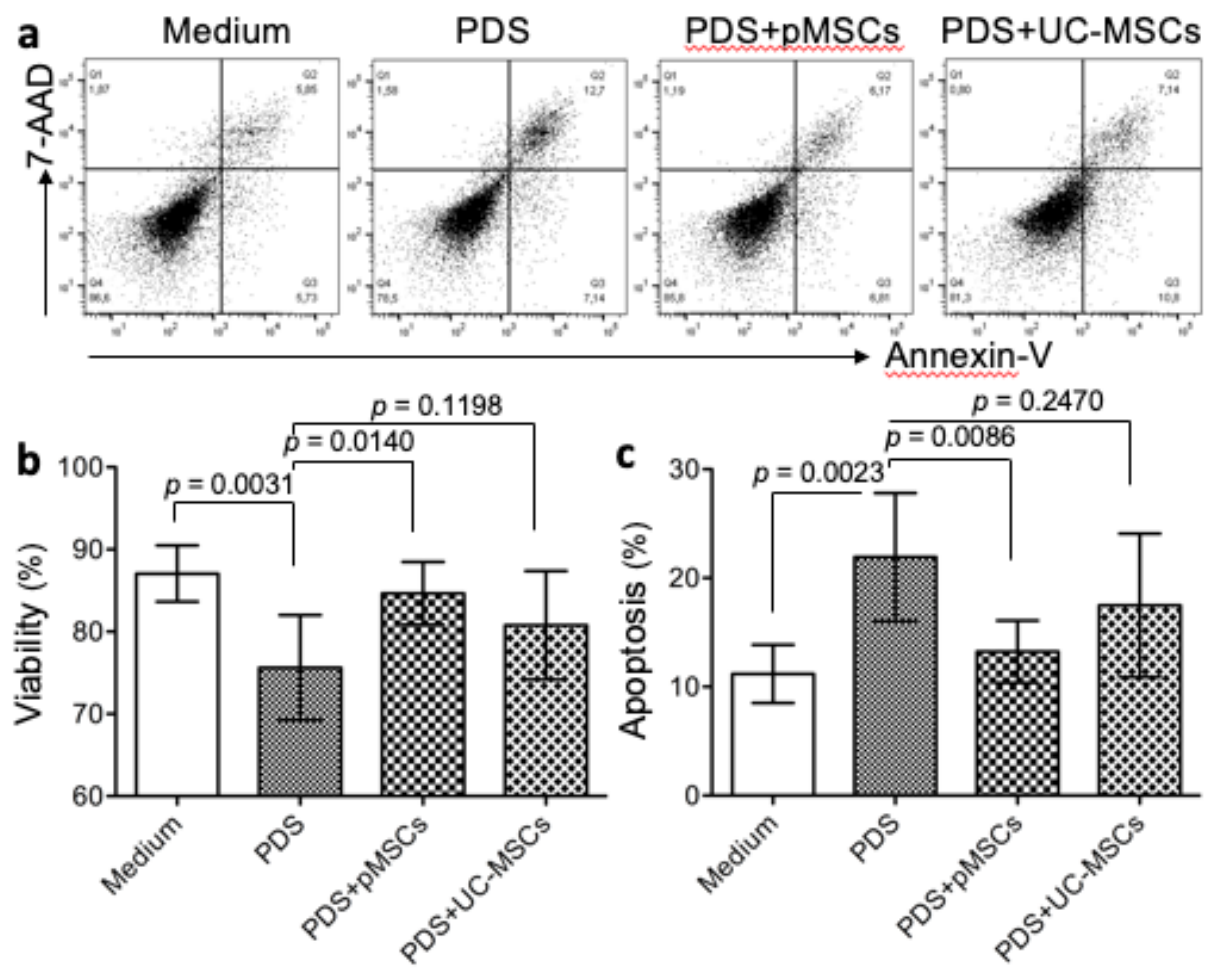

\section{Figure 9}

Different protection of HPMCs from PDS-induced cell death by between pMSCs-CM and UC-MSCs-CM. A monolayer of HPMCs was exposed to 4.25\% dextrose Dianeal PDS for 20 min, followed by 24-h incubation with either pMSCs-CM or UC-MSCs-CM. Cell viability/survival or apoptosis was measured using FACS analysis with staining with both 7-AAD and Annexin-V. (a) A typical FACS graph showing cell viability and cell death in each group. Q1: 7-AAD positive - necrotic cells; Q2 and Q3: Annexin-V positive - apoptotic cells; and Q4: both negative - viable cells. (b) Viability or survived cells in Q4. (c) Apoptosis (total of Q2 and Q3). Data are presented as the mean \pm SD of each group $(n=6)$. The difference between groups was analyzed using two-tailed t-test. 
Figure 10

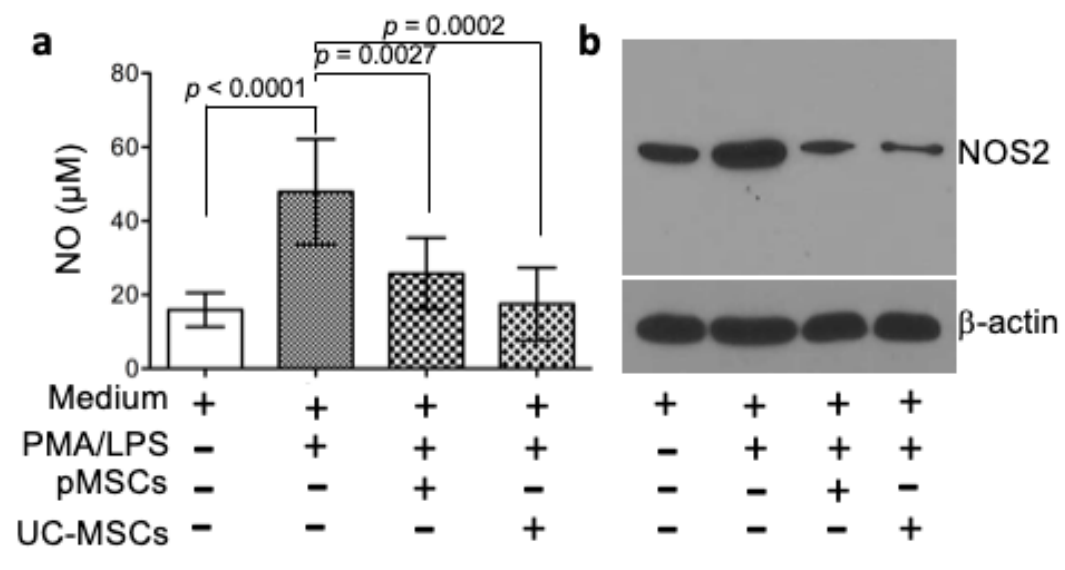

Figure 10

Different suppression of NOS 2 expression and activity in activated THP-1 by between pMSCs-CM and UC-MSCs-CM. THP-1 monocytes in cultures were activated by the addition of PMA for $24 \mathrm{~h}$, followed by the additional $24 \mathrm{~h}$ with LPS. The activated THP-1 cells were incubated with either pMSCs-CM or MUMSCs-CM. (a) Nitric oxide (NO) levels from Griess assay. Data are presented as the mean \pm SD of each group $(n=8)$. The difference between groups was analyzed using two-tailed t-test. (b) NOS 2 protein levels in Western blot analysis. Data are representative of three independent experiments.

\section{Supplementary Files}

This is a list of supplementary files associated with this preprint. Click to download.

- SupplTable1.docx

- SupplTable2.docx

- SupplTable3.docx

- SupplTable4.docx 